NBER WORKING PAPER SERIES

\title{
ABILITY TRACKING, SCHOOL COMPETITION, AND THE DISTRIBUTION OF EDUCATIONAL BENEFITS
}

\author{
Dennis Epple \\ Elizabeth Newlon \\ Richard Romano \\ Working Paper 7854 \\ http://www.nber.org/papers/w7854 \\ NATIONAL BUREAU OF ECONOMIC RESEARCH
1050 Massachusetts Avenue
Cambridge, MA 02138
August 2000
}

The authors thank Thomas Downes, Thomas Nechyba, Robert Schwab, and two anonymous referees for helpful comments as well as seminar participants at the 1996 ASSA Meetings, the 1996 Public Choice Meetings, the May 1997 MacArthur Research Network Conference on Inequality and Economic Performance (Cambridge, MA), Texas A\&M University, the University of British Columbia, the University of Houston, and the University of Southern California. We appreciate financial support provided for this research by the National Science Foundation and MacArthur Foundation. The views expressed herein are those of the authors and not necessarily those of the National Bureau of Economic Research.

(C) 2000 by Dennis Epple, Elizabeth Newlon, and Richard Romano. All rights reserved. Short sections of text, not to exceed two paragraphs, may be quoted without explicit permission provided that full credit, including (C) notice, is given to the source. 
Ability Tracking, School Competition, and the Distribution of Educational Benefits

Dennis Epple, Elizabeth Newlon, and Richard Romano

NBER Working Paper No. 7854

August 2000

JEL No. H70, I21

\begin{abstract}
To study the effects of ability grouping on school competition, we develop a theoretical and computational model of tracking in public and private schools. We examine tracking's consequences for the allocation of students of differing abilities and income within and between public and private schools. Private schools tend to attract the most able and wealthiest students, and rarely track in equilibrium. Public sector schools can maximize attendance by tracking students. Public schools retain a greater proportion of higher-ability students by tracking, but lose more wealthy, lower-ability students to the private sector. Consequently, socioeconomic status is a predictor of track assignment in public schools. For the entire population, public-sector tracking has small aggregate effects on achievement and welfare, but results in significant redistribution from lower- to higher-ability students.
\end{abstract}

Dennis Epple

Graduate School of Industrial Administration

Carnegie Mellon University

Pittsburgh, PA 15213

and NBER

epple@cmu.edu

Richard Romano

University of Florida

Gainesville, FL 32611
Elizabeth Newlon

University of Kentucky

Lexington, KY 40506

enewlon@pop.uky.edu 


\section{Introduction}

Grouping students based on aptitude measures such as scores on standardized exams (ability tracking) is pervasive in the U.S. ${ }^{1}$ For example, public school teachers reported that only 14.4 percent of eighth-grade students and 10.8 percent of tenth-grade students were in heterogeneous (untracked) math classes in 1988 and 1990 respectively (Rees, Argys, and Brewer, 1996). ${ }^{2}$ The practice of tracking varies considerably on multiple dimensions, but conforms to several general observations. ${ }^{3}$ First, track placement is positively correlated with socioeconomic status: Household income distributions in higher-ability tracks stochastically dominate those in lower tracks (see, e.g., Rees, et.al., Tables 4 and 5). Second, tracking programs are frequently limited in scope in that students are placed in tracked classes for only a subset of subjects (see footnote 3 ). Last, nonCatholic private schools engage in significantly less tracking. ${ }^{4}$ While conceptualization and quantification of the effects of tracking on students has and continues to be a focus of study by social scientists, we are aware of no research that views tracking as an equilibrium phenomenon. ${ }^{5}$ This paper develops a theoretical and computational model of an educational market with tracking that is broadly consistent with the observed characteristics of its practice. ${ }^{6}$

Our model presumes students differ by ability and household income. Students select either a profit-maximizing, private school in a (monopolistically) competitive private sector or a taxfinanced, free public school. Any school may practice tracking and choose its scope. Household utility is increasing in student achievement, which depends on own student ability and the quality (mean ability) of the peer group with which the student attends classes. We examine market equilibrium with optimizing choices, treating the practice of tracking by public schools as exogenous. $^{7}$

We find that public school tracking, of limited scope, serves to maximize public school attendance. In contrast, competitive pressures preclude the practice of tracking by private schools 
quite generally. Such an equilibrium is consistent with the positive correlation of income and track placement among public school students, even absent correlation of household income and student ability in the population. The key here is that public-school tracking serves to retain relatively higher-income, higher-ability students who qualify for the high track and would attend private schools in the absence of tracking, while driving higher-income, lower-ability students that fail to qualify into private schools. For students who qualify for the high track and attend public school whether or not tracking is present, elimination of tracking would reduce achievement and welfare. The reverse is true for those who do not qualify for the high track. Effects on those who attend private schools in either equilibrium are more complicated. The underlying factor here is that tracking on the part of public schools results in more intense competition for high-ability students. Hence, private-school tuition discounts to high-ability students that arise in equilibrium are greater when public schools track than when they do not.

Section 2 develops the theoretical model. Theoretical results are presented in Section 3. Section 4 consists of the computational model and results, and Section 5 offers some concluding remarks. Selected details are provided in an appendix.

\section{The Model}

A. Household and Educational Technology. The model of the educational process is an extension of that in Epple and Romano (1998) to the consideration of student tracking in schools. ${ }^{8}$ Household income is denoted $y$, and each household has a student of ability $b$. The joint marginal distribution of ability and income in the population is denoted $f(b, y)$, and is assumed to be continuous and positive on its support, $\mathrm{S} \equiv\left(0, \mathrm{~b}_{\max }\right] \times\left(0, \mathrm{y}_{\max }\right]$. All students attend a school since we assume free public schooling is preferred to no schooling. The household decision maker's utility function, $\mathrm{U}(\cdot)$, is increasing in numeraire consumption and the educational achievement of the 
household's student, and continuous and twice differentiable in both arguments. Achievement, $\mathrm{a}=\mathrm{a}(\theta, \mathrm{b})$, is a differentiable and increasing function of the student's ability and the educational quality of the student's track in the school attended, $\theta$. Let $y_{t}$ denote after-tax income and $p$ tuition expenditure, the latter equal to zero if a public school is attended. Thus, $U=U\left(y_{t}-p, a(\theta, b)\right)$, with $\mathrm{U}_{1}, \mathrm{U}_{2}, \mathrm{a}_{1}$, and $\mathrm{a}_{2}$ all positive.

Peer student abilities exclusively determine track qualities in our model, highlighting the effects of ability tracking. ${ }^{9}$ We permit at most two tracks in a school for simplicity. With tracking, students are assigned to a high or low track by the process discussed below. Track quality equals the mean ability of peer students per unit of time in classes. Below we extend the model to allow quality gains from reducing variability in student ability due to curriculum specialization. A "mixing" value, $\mathrm{m} \in[0,1]$, equals the proportion of class time (proportion of subjects studied) over which students attend non-ability-segregated or "mixed" classes, with the remaining time (subjects studied) in classes with students assigned exclusively to their track. Let $\bar{b}_{\mathrm{h}}>\overline{\mathrm{b}}_{\ell}$ denote the mean ability of students assigned to the high and low tracks respectively, and $\bar{b}$ the mean student ability in the school. Quality of track $i \in\{l, h\}$ is then given by

$$
\theta_{i}=(1-m) \bar{b}_{i}+m \bar{b} .
$$

Pure tracking has $\mathrm{m}=0$ and no tracking $\mathrm{m}=1$.

$\mathrm{U}$ is also assumed to satisfy everywhere the "single-crossing" condition:

$$
\partial\left[\frac{\partial \mathrm{U} / \partial \theta}{\partial \mathrm{U} / \partial \mathbf{y}_{\mathrm{t}}}\right] / \partial \mathbf{y}_{\mathrm{t}}>0
$$

Hence, for students of the same ability, any indifference curve in the $(\theta, p)$-plane of a higher-income household cuts any indifference curve of a lower-income household from below. This condition corresponds to an income elasticity of demand for educational quality that is positive at all qualities for all types. One set of sufficient conditions on $U$ for $\mathbf{S C I}$ is $U_{11} \leq 0$ and $U_{12} \geq 0$, with at least one 
having strict inequality. ${ }^{10}$

Preferences for school quality might also depend on ability. We say preferences satisfy weak single crossing in ability if $\partial\left[\frac{\partial \mathrm{U} / \partial \theta}{\partial \mathrm{U} / \partial \mathrm{y}_{\mathrm{t}}}\right] / \partial \mathrm{b} \geq 0$, which implies a weakly positive ability elasticity of demand for quality. However, because the pertinent empirical evidence is mixed and sparse and because only one of our theoretical results (stratification by ability) depends on this elasticity, we otherwise invoke no restrictions on this elasticity in our theoretical analysis. ${ }^{11}$ In our computational model and to illustrate our more general theoretical results, we adopt a Cobb-Douglas specification of the utility function:

$$
\mathrm{U}=\left(\mathrm{y}_{\mathrm{t}}-\mathrm{p}\right) \mathrm{a}(\theta, \mathrm{b}) ; \quad \mathrm{a}(\theta, \mathrm{b})=\theta^{\gamma} \mathrm{b}^{\beta} ; \beta>0, \gamma>0
$$

While (2) satisfies SCI, it embodies the "neutral" assumption of zero ability elasticity of demand: $\partial\left[\frac{\partial \mathrm{U} / \partial \theta}{\partial \mathrm{U} / \partial \mathrm{y}_{\mathrm{t}}}\right] / \partial \mathrm{b}=0$

A school's costs depend only on the number of students in each track since we hold fixed the quality of educational inputs other than peer student ability (see footnote 9 ). Let $\mathrm{k}_{\mathrm{i}}, \mathrm{i} \in\{\ell, \mathrm{h}\}$, equal the number of students in track $\mathrm{i}$, and $\mathrm{k} \equiv \mathrm{k}_{\ell}+\mathrm{k}_{\mathrm{h}}$ the number of students in the school. $\mathrm{C}\left(\mathrm{k}_{\ell}, \mathrm{k}_{\mathrm{h}}\right)$ denotes total cost. A more general specification would have $\mathrm{m}$ as another argument. We do require $\mathrm{C}\left(\mathrm{k}_{\ell}, \mathrm{k}_{\mathrm{h}}\right)=\mathrm{C}\left(\mathrm{k}_{\ell}+\mathrm{k}_{\mathrm{h}}, 0\right)=\mathrm{C}\left(0, \mathrm{k}_{\ell}+\mathrm{k}_{\mathrm{h}}\right)$ if $\mathrm{m}=1$, i.e., if there is no real tracking. We say that diseconomies (economies) of scope in tracking are present if:

$$
\mathrm{C}\left(\mathrm{k}_{\ell}, \mathrm{k}_{\mathrm{h}}\right) \geq(\leq) \mathrm{C}\left(\mathrm{k}_{\ell}, 0\right)+\mathrm{C}\left(0, \mathrm{k}_{\mathrm{h}}\right) \quad \forall \quad \mathrm{k}_{\mathrm{i}}>0, \quad \mathrm{i} \in\{1, \mathrm{~h}\}
$$

In our computational analysis we investigate the neutral case of "constant scope economies," i.e., where (3) holds with equality. There we assume track costs are given by

$$
\mathrm{V}\left(\mathrm{k}_{\mathrm{i}}\right)+\mathrm{F} ; \mathrm{V}^{\prime}>0, \mathrm{~V}^{\prime \prime}>0
$$

which also equals the cost of a school that does not track having $\mathrm{k}=\mathrm{k}_{\mathrm{i}}$. For this specification, let $\mathrm{k}_{\mathrm{i}}^{*}$ denote the "efficient scale" of a track (or school in the no-tracking case): 


$$
\mathrm{k}_{\mathrm{i}}^{*} \equiv \operatorname{ARGMIN}\left[\mathrm{C}\left(\mathrm{k}_{\mathrm{i}}\right) / \mathrm{k}_{\mathrm{i}}\right] .
$$

Presuming the presence of scale economies in schooling is realistic (Kenny, 1982) and precludes an unrealistic continuum of private schools that would otherwise result (Epple and Romano, 1998).

B. Public Sector Schools. Public sector schools all follow the same policies and are homogeneous. ${ }^{12}$ They offer free admission to all students. They track by ability using the same threshold ability, B, and adopt the same mixing value, $\mathrm{m}$. Students are assigned to the upper (lower) track as their own ability $\mathrm{b} \geq(<)$ B. ${ }^{13}$ Rather than postulate an objective function for public school administrators, we treat $\mathrm{B}$ and $\mathrm{m}$ as exogenous and examine (computationally) how varying these parameters affects measures of public school performance like the relative size of the public sector.

Public sector schooling is financed by a proportional income tax, t, paid by all households, whether or not the household's child attends public school. The public sector chooses the integer number of schools to minimize the total cost of providing schooling given their policy parameters, cost function, and household choices of public or private schooling. The tax rate adjusts with household choices to balance the public-sector budget. Note that one can think of the public sector as one (likely large) public school.

C. Private Sector Schools. Private sector schools maximize profits and there is free entry and exit. ${ }^{14}$ They can practice tracking and optimally choose the mixing value $\mathrm{m}$, but again we allow no more than two tracks for simplicity. Student type is observable, implying tuition and track assignment can be conditioned on ability and income as competition permits. ${ }^{15}$ Note that track assignment need not depend only on ability. Private schools are an example of clubs with "nonanonymous crowding" (Scotchmer and Wooders, 1987 and Scotchmer, 1997) because of the peergroup externalities, and we model private school behavior following the literature on competitive club economies. In particular, private schools maximize profits as utility takers (see Scotchmer, 
1994), meaning they believe they can attract any student-type by offering admission and track assignment at a tuition yielding at least the maximum utility the student could obtain elsewhere.

We now develop a private school's optimization problem. It is convenient and without loss of generality to describe schools as choosing both an admission and tuition policy. Let an i subscript, $\mathrm{i}=1,2, . ., \mathrm{n}$, indicate a value for the ith private school. A zero subscript does the same for "the" public school. Let $\alpha_{i}(b, y) \in[0,1]$ denote the proportion of type $(b, y)$ in the population that school $\mathrm{i}$ admits, with any $\alpha_{0}(\mathrm{~b}, \mathrm{y})$ "optimal" for the public sector. (The equilibrium $\alpha_{0}(\mathrm{~b}, \mathrm{y})$ is determined by the residual demand for public education.) Let $\varphi_{\mathrm{i}}(\mathrm{b}, \mathrm{y}) \in[0,1]$ denote the proportion of school i's admitted students of type (b,y) assigned to the high track, hence, $1-\varphi_{i}$ the proportion assigned to the low track. Public school policy dictates that $\varphi_{0}=1(0)$ for $b \geq(<)$ B. Finally, let $\mathrm{p}_{\mathrm{ih}}(\mathrm{b}, \mathrm{y})$ and $\mathrm{p}_{\mathrm{i} \ell}(\mathrm{b}, \mathrm{y})$ denote school i's tuition functions for the high and low tracks respectively. Public school policy dictates that $\mathrm{p}_{0 \mathrm{~h}}=\mathrm{p}_{0 \ell}=0$ for all $(\mathrm{b}, \mathrm{y})$, but applicable subject to track qualification.

To describe the constraint on a private school's tuition function, let $\mathrm{U}_{\mathrm{i}}^{*}(\mathrm{~b}, \mathrm{y})$ denote the utility type $(b, y)$ can obtain by choosing the best available alternative to school $\mathrm{i}$ in equilibrium:

$$
\begin{aligned}
& \left.\mathrm{U}_{\mathrm{i}}^{*}(\mathrm{~b}, \mathrm{y}) \equiv \operatorname{MAX} \underset{\mathrm{j} \neq \mathrm{i}}{\operatorname{MAX}} \mathrm{U}\left(\mathrm{y}_{\mathrm{t}}-\mathrm{p}_{\mathrm{j} \ell}(\mathrm{b}, \mathrm{y}), \mathrm{a}\left(\theta_{\mathrm{j} \ell}, \mathrm{b}\right)\right) ; \underset{\mathrm{j} \neq \mathrm{i}}{\operatorname{MAX}} \mathrm{U}\left(\mathrm{y}_{\mathrm{t}}-\mathrm{p}_{\mathrm{jh}}(\mathrm{b}, \mathrm{y}), \mathrm{a}\left(\theta_{\mathrm{jh}}, \mathrm{b}\right)\right)\right] \\
& \mathrm{j} \in\left\{0,1, ., \mathrm{n} ; \alpha_{\mathrm{j}}(\mathrm{b}, \mathrm{y})>0 \quad \mathrm{j} \in\left\{0,1, ., \mathrm{n} ; \alpha_{\mathrm{j}}(\mathrm{b}, \mathrm{y})>0\right.\right. \\
& \text { and } \left.\left.\varphi_{\mathrm{j}}<1 \text { is optimal for } \mathrm{j}\right\} \quad \text { and } \varphi_{\mathrm{j}}>0 \text { is optimal for } \mathrm{j}\right\}
\end{aligned}
$$

This best alternative utility is the maximum attainable at any other school/track, conditional on being acceptable in that school/track.

Private school i's optimization problem can be written:

$$
\operatorname{MAX} \pi_{\mathrm{i}} \equiv \iint_{\mathrm{S}}\left\{\mathrm{p}_{\mathrm{i} \ell}(\mathrm{b}, \mathrm{y})\left[1-\varphi_{\mathrm{i}}(\mathrm{b}, \mathrm{y})\right]+\mathrm{p}_{\mathrm{ih}}(\mathrm{b}, \mathrm{y}) \varphi_{\mathrm{i}}(\mathrm{b}, \mathrm{y})\right\} \alpha_{\mathrm{i}}(\mathrm{b}, \mathrm{y}) \mathrm{f}(\mathrm{b}, \mathrm{y}) \mathrm{dbdy}-\mathrm{C}\left(\mathrm{k}_{\mathrm{i} \ell}, \mathrm{k}_{\mathrm{ih}}\right)
$$

s.t.

$$
\begin{gathered}
\alpha_{\mathrm{i}}(\mathrm{b}, \mathrm{y}) \in[0,1] \forall(\mathrm{b}, \mathrm{y}) \in \mathrm{S} ; \\
\varphi_{\mathrm{i}}(\mathrm{b}, \mathrm{y}) \in[0,1] \forall(\mathrm{b}, \mathrm{y}) \in \mathrm{S} ; \\
\mathrm{m}_{\mathrm{i}} \in[0,1] ;
\end{gathered}
$$




$$
\begin{gathered}
\mathrm{k}_{\mathrm{i} \ell}=\iint_{\mathrm{S}}\left(1-\varphi_{\mathrm{i}}(\mathrm{b}, \mathrm{y})\right) \alpha_{\mathrm{i}}(\mathrm{b}, \mathrm{y}) \mathrm{f}(\mathrm{b}, \mathrm{y}) \mathrm{dbdy} \\
\mathrm{k}_{\mathrm{ih}}=\iint_{\mathrm{S}} \varphi_{\mathrm{i}}(\mathrm{b}, \mathrm{y}) \alpha_{\mathrm{i}}(\mathrm{b}, \mathrm{y}) \mathrm{f}(\mathrm{b}, \mathrm{y}) \mathrm{dbdy} ; \\
\overline{\mathrm{b}}_{\mathrm{i} \ell}=\frac{1}{\mathrm{k}_{\mathrm{i} \ell}} \int_{\mathrm{S}} \int_{\mathrm{i}} \mathrm{b}\left(1-\varphi_{\mathrm{i}}(\mathrm{b}, \mathrm{y})\right) \alpha_{\mathrm{i}}(\mathrm{b}, \mathrm{y}) \mathrm{f}(\mathrm{b}, \mathrm{y}) \mathrm{dbdy} ; \\
\overline{\mathrm{b}}_{\mathrm{ih}}=\frac{1}{\mathrm{k}_{\mathrm{ih}}} \int_{\mathrm{S}} \mathrm{b} \varphi_{\mathrm{i}}(\mathrm{b}, \mathrm{y}) \alpha_{\mathrm{i}}(\mathrm{b}, \mathrm{y}) \mathrm{f}(\mathrm{b}, \mathrm{y}) \mathrm{dbdy} ; \\
\left.\overline{\mathrm{b}}_{\mathrm{i}}=\mathrm{k}_{\mathrm{i} \ell} \overline{\mathrm{b}}_{\mathrm{i} \ell}+\mathrm{k}_{\mathrm{ih}} \overline{\mathrm{b}}_{\mathrm{ih}}\right) /\left(\mathrm{k}_{\mathrm{i} \ell}+\mathrm{k}_{\mathrm{ih}}\right) ; \\
\theta_{\mathrm{i} \ell}=\left(1-\mathrm{m}_{\mathrm{i}}\right) \overline{\mathrm{b}}_{\mathrm{i} \ell}+\mathrm{m}_{\mathrm{i}} \overline{\mathrm{b}}_{\mathrm{i}} ; \\
\theta_{\mathrm{ih}}=\left(1-\mathrm{m}_{\mathrm{i}}\right) \overline{\mathrm{b}}_{\mathrm{ih}}+\mathrm{m}_{\mathrm{i}} \overline{\mathrm{b}}_{\mathrm{i}} ; \\
\mathrm{U}\left(\mathrm{y}_{\mathrm{t}}-\mathrm{p}_{\mathrm{ih}}(\mathrm{b}, \mathrm{y}), \mathrm{a}\left(\theta_{\mathrm{ih}}, \mathrm{b}\right)\right) \geq \mathrm{U}_{\mathrm{i}}^{*}(\mathrm{~b}, \mathrm{y}) \forall(\mathrm{b}, \mathrm{y}) \in \mathrm{S} ;
\end{gathered}
$$

and

$$
\mathrm{U}\left(\mathrm{y}_{\mathrm{t}}-\mathrm{p}_{\mathrm{i} \ell}(\mathrm{b}, \mathrm{y}), \mathrm{a}\left(\theta_{\mathrm{i} \ell}, \mathrm{b}\right)\right) \geq \mathrm{U}_{\mathrm{i}}^{*}(\mathrm{~b}, \mathrm{y}) \forall(\mathrm{b}, \mathrm{y}) \in \mathrm{S} .
$$

Constraint (7.1) ensures that a school admits no more of a type than exists in the population. ${ }^{16}$ Constraint (7.2) simply requires that all admitted students be assigned to one of the two tracks. The mixing choice $\mathrm{m}_{\mathrm{i}}$ is endogenous, as constrained by (7.3). Constraints (7.4) - (7.8) are definitional, and constraints (7.9) - (7.10) incorporate the technological constraints on mixing and track quality. Constraints (7.11) and (7.12) embody the utility-taking assumption, requiring that a school expects (correctly in equilibrium) to attract a student if offered the same utility obtainable elsewhere. It is without loss of generality to specify (7.11) - (7.12) to hold for all (b,y) as we have, including for students not admitted to the school or particular track, because we have specified separate school admission and track-assignment choice variables. Clearly, too, (7.11) - (7.12) can be required to 
hold with equality, since the implied tuitions are profit-maximizing for any admitted students. Then, let $\mathrm{p}^{*}\left(\mathrm{~b}, \mathrm{y}, \theta_{\mathrm{ih}}\right)$ satisfy $(7.11)$ with equality, which is type $(\mathrm{b}, \mathrm{y})$ 's reservation price to attend track $\mathrm{h}$ at school i, and equals the tuition paid by all those admitted to the track. Analogously, define $\mathrm{p}^{*}\left(\mathrm{~b}, \mathrm{y}, \theta_{\mathrm{i} \ell}\right)$ by requiring equality of (7.12).

Note that a choice not to track corresponds to setting $\varphi_{\mathrm{i}}=0$ for all (b,y), or, equivalently, $\varphi_{\mathrm{i}}=1$ for all $(\mathrm{b}, \mathrm{y})$. In this case the "choice" of $\mathrm{m}_{\mathrm{i}}$ is indeterminant and irrelevant. We provide a complete solution to problem (7) in Section 3.

D. Equilibrium. Market equilibrium can be described by the following conditions.

$$
\mathrm{U}^{*}(\mathrm{~b}, \mathrm{y})=\mathrm{U}_{\mathrm{i}}^{*}(\mathrm{~b}, \mathrm{y}) \forall(\mathrm{b}, \mathrm{y}) \in \mathrm{S}, \mathrm{i}=1,2, . ., \mathrm{n}
$$

$$
\begin{gathered}
{\left[\theta_{i h}, \theta_{i \ell}, k_{i h}, k_{i \ell}, m_{i}, p_{i h}(b, y), p_{i \ell}(b, y), \varphi_{i}(b, y), \alpha_{i}(b, y)\right]} \\
\text { satisfy problem }(7), i=1,2, \ldots, n ;
\end{gathered}
$$

$$
\pi_{\mathrm{i}}=0, \quad \mathrm{i}=1,2, . ., \mathrm{n}
$$

For all $(\mathrm{b}, \mathrm{y}) \in \mathrm{S}: \mathrm{p}_{0}(\mathrm{~b}, \mathrm{y})=0, \alpha_{0}(\mathrm{~b}, \mathrm{y}) \in[0,1]$ and $\varphi_{0}(\mathrm{~b}, \mathrm{y})=1(0)$ for $\mathrm{b} \geq(<) \mathrm{B}$;

$$
\begin{gathered}
\mathrm{k}_{0 \ell}=\iint_{\mathrm{S}}\left[1-\varphi_{0}(\mathrm{~b}, \mathrm{y})\right] \alpha_{0}(\mathrm{~b}, \mathrm{y}) \mathrm{f}(\mathrm{b}, \mathrm{y}) \mathrm{dbdy} ; \mathrm{k}_{0 \mathrm{~h}}=\iint_{\mathrm{S}} \varphi_{0}(\mathrm{~b}, \mathrm{y}) \alpha_{0}(\mathrm{~b}, \mathrm{y}) \mathrm{f}(\mathrm{b}, \mathrm{y}) \mathrm{dbdy} ; \\
\overline{\mathrm{b}}_{0 \ell}=\frac{1}{\mathrm{k}_{0 \ell}} \iint_{\mathrm{S}} \mathrm{b}\left[1-\varphi_{0}(\mathrm{~b}, \mathrm{y})\right] \alpha_{0}(\mathrm{~b}, \mathrm{y}) \mathrm{f}(\mathrm{b}, \mathrm{y}) \mathrm{dbdy} ; \quad \overline{\mathrm{b}}_{0 \mathrm{~h}}=\frac{1}{\mathrm{k}_{0 \mathrm{~h}}} \iint_{\mathrm{S}} \mathrm{b} \varphi_{0}(\mathrm{~b}, \mathrm{y}) \alpha_{0}(\mathrm{~b}, \mathrm{y}) \mathrm{f}(\mathrm{b}, \mathrm{y}) \mathrm{dbdy} ; \quad(P S P) \\
\overline{\mathrm{b}}_{0}=\frac{\left(\mathrm{k}_{0 \ell} \overline{\mathrm{b}}_{0 \ell}+\mathrm{k}_{0 \mathrm{~h}} \overline{\mathrm{b}}_{0 \mathrm{~h}}\right)}{\left(\mathrm{k}_{0 \ell}+\mathrm{k}_{0 \mathrm{~h}}\right)} ; \\
\theta_{0 \mathrm{i}}=\left(1-\mathrm{m}_{0}\right) \overline{\mathrm{b}}_{0 \mathrm{i}}+\mathrm{m}_{0} \overline{\mathrm{b}}_{0}, \mathrm{i} \in\{\ell, \mathrm{h}\} ;
\end{gathered}
$$




$$
\overline{\mathrm{ty}}=\underset{\mathrm{N} \in\{1,2, \ldots\}}{\operatorname{MIN}} \mathrm{N} \cdot \mathrm{C}\left(\frac{\mathrm{k}_{0 \ell}}{\mathrm{N}}, \frac{\mathrm{k}_{0 \mathrm{~h}}}{\mathrm{~N}}\right)
$$

and

$$
\sum_{\mathrm{i}=0}^{\mathrm{n}} \alpha_{\mathrm{i}}(\mathrm{b}, \mathrm{y})=1 \forall(\mathrm{b}, \mathrm{y}) \in \mathrm{S} .
$$

Condition UM summarizes utility maximization. Households choose a school/track that maximizes utility while taking as given school/track qualities, admission/track-assignment/tuition policies, and the tax rate. Equilibrium utility, $\mathrm{U}^{*}(\mathrm{~b}, \mathrm{y})$, satisfies $U M$ since private schools will set tuitions equal to reservation prices. Profit maximization, ПM, has been discussed. No entry by or exit of utility-taking private schools will occur if and only if the zero-profit condition ZI is satisfied. The public school policies and outcomes are described by the six lines of condition PSP, where $\mathrm{m}$ and $\mathrm{B}$ are exogenous. The last line of PSP is the public-sector balanced-budget condition, where $\mathrm{N}$ is the number of homogeneous public schools and where $\bar{y} \equiv \iint_{S} y f(b, y) d b d y$ denotes mean and aggregate income, the latter because we normalize the population to equal 1 . The final condition is market clearance; all students attend a school.

\section{Theoretical Results.}

A. Equilibrium Without Tracking. To understand the effects of tracking, we first need a characterization of equilibrium when there is no tracking in private or public schools. The properties of equilibrium in this model with no tracking are developed in Epple and Romano (1998). We briefly summarize those results here. By requiring that $\mathrm{m}$ equals 1 in all schools the simplified model without tracking is obtained. School quality, $\theta$, then simply equals mean student ability in each school (see (1)). The issue of track assignment disappears, and the private school's problem is considerably simplified. We can drop the subscript $\mathrm{j} \in\{\ell, \mathrm{h}\}$ from values describing school variables. Note that the ith private school has a single tuition function $\mathrm{p}_{\mathrm{i}}(\mathrm{b}, \mathrm{y})$. Last, this analysis employs the simple school cost function in (4) for all schools. 
The solution to the ith private school's profit maximization problem is summarized as follows:

and

$$
\begin{gathered}
\mathrm{p}_{\mathrm{i}}(\mathrm{b}, \mathrm{y})=\mathrm{p}^{*}\left(\mathrm{~b}, \mathrm{y}, \theta_{\mathrm{i}}\right) \forall(\mathrm{b}, \mathrm{y}) \in \mathrm{S} \\
\eta_{\mathrm{i}}=\frac{1}{\mathrm{k}_{\mathrm{i}}} \iint_{\mathrm{S}} \frac{\partial \mathrm{p}^{*}\left(\mathrm{~b}, \mathrm{y}, \theta_{\mathrm{i}}\right)}{\partial \theta} \alpha_{\mathrm{i}}(\mathrm{b}, \mathrm{y}) \mathrm{f}(\mathrm{b}, \mathrm{y}) \mathrm{dbdy}
\end{gathered}
$$

where

$$
\alpha_{\mathrm{i}}(\mathrm{b}, \mathrm{y})\left(\begin{array}{c}
=1 \\
\epsilon[0,1] \\
=0
\end{array}\right) \text { if } \mathrm{p}^{*}\left(\mathrm{~b}, \mathrm{y}, \theta_{\mathrm{i}}\right)\left(\begin{array}{l}
> \\
= \\
<
\end{array}\right) \operatorname{EMC}_{\mathrm{i}}(\mathrm{b}) \quad \forall(\mathrm{b}, \mathrm{y}) \in \mathrm{S} ;
$$

$$
\mathrm{EMC}_{\mathrm{i}}(\mathrm{b}) \equiv \mathrm{V}^{\prime}\left(\mathrm{k}_{\mathrm{i}}\right)+\eta_{\mathrm{i}}\left(\theta_{\mathrm{i}}-\mathrm{b}\right) .
$$

All students face a tuition to school $i$ equal to their reservation price for attending a school of quality $\theta_{i}$ by (8.1). Condition (8.2) defines a Lagrangian multiplier that equals the marginal willingness to pay for quality increases per household in the ith school's student body. We define the "effective marginal cost (EMC)" of admitting a student of ability $b$ as equal to the resource cost of educating the student minus the revenue change deriving from that student's effect on school quality. Expression (8.4) indicates the latter "peer effect" equals the change in $\theta_{\mathrm{i}}$ from admitting student of type $b$ (equal to $\frac{b-\theta_{i}}{k_{i}}$ ) multiplied by the aggregation of the optimal tuition adjustments (equal to $\mathrm{k}_{\mathrm{i}} \eta_{\mathrm{i}}$. Note that the peer-effect "cost" of admission is negative for students of ability higher than the mean ability in the school. Condition (8.3) then indicates all (no) students of type (b,y) who are willing to pay more (less) than their EMC are admitted, and indifference to admission obtains for types with $\mathrm{p}^{*}=\mathrm{EMC}_{\mathrm{i}}$.

The peer effect on quality is central to the nature of equilibrium. Private school's fully internalize this externality in admission decisions. The relative values of the $\eta$ 's across private schools of differing quality will play a role in the analysis. Below we will argue that higher quality schools are likely to be characterized by higher $\eta$ values.

Turning to market properties, the analysis is complicated by an existence problem. The 
existence problem is generic to club economics (see Scotchmer, 1994), derives from the discreteness of schools (i.e., their fixed costs), and is manifest in an inability to have all (profit-maximizing) private schools' profits equal exactly zero in general. Our resolution is to examine an "epsilon competitive equilibrium," that replaces the (ПM) and (ZП) conditions with requirements that private schools are at local profit maxima (implying satisfaction of first-order conditions) but allowing profit levels to differ from zero by a positive value $\epsilon$. Hence, entry will not occur unless $\pi_{i}>\epsilon$ for some private school, nor would an incumbent school pursue non-local changes in admission/tuition policies unless it could gain more than $\epsilon$. Of course, the smaller the value of $\epsilon$ consistent with the equilibrium, the less troubling is the approximation. In our computational analysis, we have found equilibrium with relatively small values of $\epsilon$, on the order of seven percent of school cost. The "equilibrium" results reported below apply to our approximate equilibrium as well as exact equilibrium $(\epsilon=0)$ when it exists.

To interpret the equilibrium properties, refer for an example to Figure 2a from our computational analysis. This case has no tracking in public schools (i.e., $\mathrm{m}=1)$ or private schools. The triangle in the (b,y)-plane with vertex at the origin comprises the student body or admission space of the public sector (with the vertical track boundary irrelevant since $\mathrm{m}=1$ ), and the remaining diagonal slices of the plane each correspond to the admission space of a private school. We refer to the loci that divide schools' admission spaces as boundary loci. Epple and Romano (1998) establish Results 1 through 4 below.

Result 1. A strict hierarchy of schools results with the public sector having the lowest ability peer group: $\theta_{\mathrm{n}}>\theta_{\mathrm{n}-1}>\ldots>\theta_{1}>\theta_{0}$.

Result 2. a. Along a boundary locus between schools i and j, $p_{i}=E M C_{i}(b)$ and $p_{j}=E C_{j}(b)$ for any $i$ and/or $j \neq 0$ (i.e., for private schools). Private school pricing on boundary loci is strictly 
according to ability.

b. $\mathrm{p}_{\mathrm{i}}(\mathrm{b}, \mathrm{y})>\mathrm{EMC}_{\mathrm{i}}(\mathrm{b})$ for $\mathrm{i} \neq 0$ in the interior of private school i's admission space; private school pricing off boundary loci depends on income.

c. The attendance pattern is the same as if all private schools instead set $p_{i}$ equal to the equilibrium $\mathrm{EMC}_{\mathrm{i}}$ for all students. ${ }^{17}$

Result 3. a. Student choice of school is characterized by stratification by income (SBI) meaning, for given ability, attendance at a higher quality school implies higher household income.

b. If preferences satisfy weak single crossing in ability and the $\eta$ 's weakly ascend in private schools (i.e., $\eta_{n} \geq \eta_{n-1} \geq \ldots \geq \eta_{1}$ ), then stratification by ability (SBA), analogously defined, also characterizes school choice.

The minimum quality of public sector schools in Result 1 is simply because public schools are free and open to all, while at least some students must pay positive tuition to any private school. The strict hierarchy among private schools of Result 1 derives from SCI and the associated incentive of higher-income types to compensate higher-ability types for attending "their" schools. In any allocation with homogenous private schools, a profit opportunity would be unexploited. Profits could be increased by adjusting tuitions so as to either attract from the homogeneous competitor more relatively higher-income, higher-ability students while expelling the same number of relatively lower-income, lower-ability students, thus improving quality; or by doing the reverse. This amounts to refining the partition of students to a more "diaganolized" one as in Figure 2a.

A cross subsidization from relatively higher-income, lower-ability students to relatively higher-ability, lower-income students that supports the strict hierarchy of private schools is seen in Result 2. Along boundary loci students are indifferent to which of the adjacent schools they attend, implying perfect competition for these students and tuition equal to effective marginal cost. Here 
private school tuitions satisfy the middle line of (8.3). Merit aide in school $\mathrm{i}$ is given by discounting tuition to ability at rate $\eta_{i}$, as $\mathrm{EMC}_{\mathrm{i}}$ declines moving down a boundary locus of school i. An implication is that some higher-ability students might pay negative tuition, i.e., receive fellowships, an outcome we find in realistically calibrated models. Students of type in the interior of a private school's admission space would have a strict preference for that school if it charged tuition equal to EMC. This is because preference for quality rises with income (SCI) while EMC is independent of income. The school increases tuition to such students, squeezing away all consumer surplus. This price discrimination is severely limited by competition and, because it is of the first degree, the allocation is as though schools compete perfectly (Results $2 \mathrm{c}$ ).

Result 3a's assertion of SBI follows easily from the normality of demand for educational quality (SCI again). Because of the discounting to ability, one expects to also find SBA. However, there is a potential for this effect to be offset if preference for quality declines with ability. Hence, we must assume weak single crossing in ability to guarantee SBA. In addition, if lower quality schools were to give higher discounts to ability (i.e., if $\eta$ 's fail to weakly ascend), then weaker schools might attract higher ability students over some ranges. Because $\eta_{i}$ is the willingness to pay for quality increases per student in school $\mathrm{i}$, we expect it to rise with school quality due to SCI and that equilibrium is characterized by income stratification. We have consistently found strictly ascending $\eta$ 's in varied computational analysis. Although a reversal of ascending $\eta$ 's seems pathological, we have not been able to reject it theoretically. ${ }^{18}$ The combination of SBI and SBA conforms to the diagonal admission spaces of private schools. ${ }^{19}$

We now turn to normative results. Pareto efficiency requires: (A) a student allocation that internalizes the peer-group externality given the number of schools; and (B) entry whenever aggregate household net willingness to pay for an allocation with one more school exceeds the change in all schools' costs. An equilibrium without a public sector would satisfy condition A, but 
not condition B. Effective marginal cost includes the marginal value of the peer group externality, implying $\mathrm{EMC}_{\mathrm{i}}(\mathrm{b})$ equals the social marginal cost of attendance at school $\mathrm{i}$ by student of ability $\mathrm{b}$. An equilibrium with only private schools then satisfies efficiency condition A by Result $2 \mathrm{c}$. However, entry to the point of zero profits entails externalities so that condition B fails to hold in a purely private equilibrium. Fixed costs, hence the finite size of an entrant, underlie the entry externalities as in other models of monopolistic competition.

Introduction of the free public sector implies deviations from both efficiency conditions. In general, the public sector displaces multiple differentiated private schools, substituting the equivalent of one "large" homogeneous school. This effective reduction in the number of schools is without attention to costs and benefits, implying a deviation from efficiency condition B. Free tuition to public schools violates condition A. By reallocating students between the public sector and private school 1 near their shared boundary locus, Paretian gains are feasible. Some or all students near the boundary locus in the public sector have positive social cost of education and should be shifted into private school.

Collecting these results, we have:

Result 4. a. The allocation in a fully private equilibrium is (Pareto) efficient given the number of schools. The equilibrium number of schools is not, however, generally efficient.

b. The public-private sector equilibrium has neither an efficient number of schools, nor an efficient student allocation given the number of schools.

The normative results above treat educational achievement as a consumption good. An alternative interpretation of the model views achievement as an investment good, with offspring income a linear function of achievement. Household utility is a linear combination of utility of parental consumption and utility of offspring's consumption. Efficiency requires an allocation of 
types across schools that maximizes aggregate achievement (net of the relative cost of education).

For the Cobb-Douglas achievement specification, the efficient allocation then entails ability stratification but no income stratification. Our positive results carry over if households face imperfect loan markets for financing education that are binding. In particular, the relevant indirect household utility function then satisfies SCI. The stratification by income that characterizes equilibrium with private schools then implies inefficiency.

To accommodate both interpretations, we examine the consequences of tracking for two welfare measures in the computational analysis. Relevant to achievement as a consumption good, we calculate changes in households' compensating variation. Relevant to achievement as an investment good, we calculate changes in a normed measure of student achievement discussed below.

B. Equilibrium with Tracking. Now allow private school $i$ to track and consider its optimization problem (7). We suppress the i subscript for the time being. In addition to the constraints themselves, the first-order conditions are:

$$
\begin{gathered}
\mathrm{p}_{\mathrm{j}}(\mathrm{b}, \mathrm{y})=\mathrm{p}^{*}\left(\mathrm{~b}, \mathrm{y}, \theta_{\mathrm{j}}\right), \mathrm{j} \in\{\ell, \mathrm{h}\} \forall(\mathrm{b}, \mathrm{y}) \in \mathrm{S} ; \\
\eta_{\ell}=\frac{1}{\mathrm{k}_{\ell}} \iint_{\mathrm{S}} \frac{\partial \mathrm{p}^{*}\left(\mathrm{~b}, \mathrm{y}, \theta_{\ell}\right)}{\partial \theta}(1-\varphi(\mathrm{b}, \mathrm{y})) \alpha(\mathrm{b}, \mathrm{y}) \mathrm{dbdy} \\
\eta_{\mathrm{h}}=\frac{1}{\mathrm{k}_{\mathrm{h}}} \iint_{\mathrm{S}} \frac{\partial \mathrm{p}^{*}\left(\mathrm{~b}, \mathrm{y}, \theta_{\mathrm{h}}\right)}{\partial \theta} \varphi(\mathrm{b}, \mathrm{y}) \alpha(\mathrm{b}, \mathrm{y}) \mathrm{dbdy} ; \\
\alpha(\mathrm{b}, \mathrm{y})\left(\begin{array}{l}
=1 \\
\epsilon[0,1] \\
=0
\end{array}\right) \text { if } \varphi(\mathrm{b}, \mathrm{y})\left[\mathrm{p}^{*}\left(\mathrm{~b}, \mathrm{y}, \theta_{\mathrm{h}}\right)-\mathrm{EMC}_{\mathrm{h}}(\mathrm{b})\right]+ \\
(1-\varphi(\mathrm{b}, \mathrm{y}))\left[\mathrm{p}^{*}\left(\mathrm{~b}, \mathrm{y}, \theta_{\ell}\right)-\mathrm{EMC}_{\ell}(\mathrm{b})\right]\left(\begin{array}{l}
> \\
= \\
<
\end{array}\right) 0 \quad \forall(\mathrm{b}, \mathrm{y}) \in \mathrm{S} ; \\
\varphi(\mathrm{b}, \mathrm{y})\left(\begin{array}{c}
=1 \\
\epsilon[0,1] \\
=0
\end{array}\right) \text { if } \mathrm{p}^{*}\left(\mathrm{~b}, \mathrm{y}, \theta_{\mathrm{h}}\right)-\mathrm{EMC}_{\mathrm{h}}(\mathrm{b})\left(\begin{array}{l}
> \\
=
\end{array}\right) \mathrm{p}^{*}\left(\mathrm{~b}, \mathrm{y}, \theta_{\ell}\right)-\mathrm{EMC}_{\ell}(\mathrm{b}) \forall \quad(\mathrm{b}, \mathrm{y}) \in \mathrm{S} ;
\end{gathered}
$$

and 


$$
\mathrm{m}\left(\begin{array}{l}
=1 \\
\in[0,1] \\
=0
\end{array}\right) \text { if }\left(\overline{\mathrm{b}}_{\mathrm{h}}-\overline{\mathrm{b}}_{\ell}\right)\left(\eta_{\mathrm{h}}-\eta_{\ell}\right)\left(\begin{array}{c}
< \\
= \\
>
\end{array}\right) 0
$$

where

$$
\mathrm{EMC}_{\mathrm{h}}(\mathrm{b}) \equiv \frac{\partial \mathrm{C}}{\partial \mathrm{k}_{\mathrm{h}}}+(1-\mathrm{m})\left(\overline{\mathrm{b}}_{\mathrm{h}}-\mathrm{b}\right) \eta_{\mathrm{h}}+\mathrm{m}(\overline{\mathrm{b}}-\mathrm{b})\left[\frac{\mathrm{k}_{\mathrm{h}}}{\mathrm{k}} \eta_{\mathrm{h}}+\frac{\mathrm{k}_{\ell}}{\mathrm{k}} \eta_{\ell}\right]
$$

and

$$
\mathrm{EMC}_{\ell}(\mathrm{b}) \equiv \frac{\partial \mathrm{C}}{\partial \mathrm{k}_{\ell}}+(1-\mathrm{m})\left(\overline{\mathrm{b}}_{\ell}-\mathrm{b}\right) \eta_{\ell}+\mathrm{m}(\overline{\mathrm{b}}-\mathrm{b})\left[\frac{\mathrm{k}_{\mathrm{h}}}{\mathrm{k}} \eta_{\mathrm{h}}+\frac{\mathrm{k}_{\ell}}{\mathrm{k}} \eta_{\ell}\right] .
$$

Most of the conditions have very similar interpretations to those when tracking is precluded. Students face their reservation prices by (9.1), but now a different one for each track. Conditions (9.2) and (9.3) describe the marginal value of changes in quality per student of those in the low and high tracks respectively. By (9.5), all students are assigned to the track that maximizes the difference between their reservation price for the track and effective marginal cost of admission to the track. There is a strict preference for assigning almost every student, i.e., $\varphi$ will equal 0 or 1 except along a one-dimensional track boundary in the (b,y)-plane. The admission criterion (9.4) is then seen to be analogous to that in the case of no tracking. Condition (9.6) describes the mixing choice discussed further below. Expressions (9.7) and (9.8) define respectively the effective marginal cost of assignment of student with ability $\mathrm{b}$ to the high and low tracks. As in the no-tracking case, effective marginal cost is the sum of the resource cost and the "cost" of the peer externality. Now the latter is a weighted sum of the revenue changes garnered from other students that attend the assigned student's track and from the entire student body, the weights dependent on the degree of mixing. Consider, for example, the externality value of a student assigned to the low track with ability higher than the mean there, but lower than the entire school's mean ability $\left(\bar{b}_{\ell}<\mathrm{b}<\overline{\mathrm{b}}\right)$. From (9.8), the student's admission and track assignment has a positive effect on the lower-track quality, in and of itself allowing higher tuitions in the lower track. Hence, the negative (second) cost term on the right side of (9.8). Countering this is a negative impact on the mixed classes, with the effect of lowering tuitions to all students (i.e., the third term in (9.8)). 
Recall that $\mathrm{m}=1$ corresponds to no tracking. ${ }^{20}$ For $\mathrm{m}<1, \overline{\mathrm{b}}_{\mathrm{h}}>\overline{\mathrm{b}}_{\ell}$ by definition of the tracks. From (9.6), then:

Lemma 1. $\quad \eta_{\mathrm{h}} \geq \eta_{\ell}$ if $\mathrm{m} \in[0,1)$.

Henceforth, when we refer to the practice of tracking, we mean the non-degenerate case with $\mathrm{m}<1$. When a private school tracks, the partition satisfies Proposition 1 .

Proposition 1. There is stratification by income across a private school's tracks. Assuming alternative utility, $\mathrm{U}_{\mathrm{i}}^{*}(\mathrm{~b}, \mathrm{y})$, is continuous in $(\mathrm{b}, \mathrm{y})$ and for Cobb-Douglas preference/achievement, stratification by ability across private school i's tracks also results.

The proof is in the appendix. The two types of within-school stratification across tracks arise for analogous reasons to the across-school stratification induced by private schools that cannot track (Result 3 above). The proof clarifies that Cobb-Douglas utility is not necessary to get both forms of stratification. SCI is enough for stratification by income, and SCI and weak single crossing in ability are "likely" to be enough for stratification by ability. The continuity assumption on $\mathrm{U}_{\mathrm{i}}^{*}(\mathrm{~b}, \mathrm{y})$ amounts to assuming that the public sector is not tracking, since public sector tracking could cause a discontinuity in $\mathrm{U}_{\mathrm{i}}^{*}(\mathrm{~b}, \mathrm{y})$ at $\mathrm{B}$ and an upward jump in the $(\mathrm{b}, \mathrm{y})$ plane of the track boundary (violating ability stratification). We do not pursue this issue further here since it does not arise in the analysis below of market equilibrium, although its analogue for public sector schools does arise and is studied. None of our other results require the restriction on $U_{i}^{*}(b, y)$.

Given SCI and the partition across tracks, it is likely that $\eta_{\mathrm{h}}>\eta_{\ell}$ (as it is likely that $\eta^{\prime}$ 's will strictly ascend in the model without tracking). Then:

Proposition 2. Private school tracking has $\mathrm{m}=0$ if $\eta_{\mathrm{h}}>\eta_{\ell}$. 
This follows immediately from (9.6). Hence, in most cases, tracking in private schools will have no mixing across tracks.

Combining Propositions 1 and 2 we see that private-school tracking produces a similar partition of students as results in equilibrium when private schools cannot track. The profit gains from tracking by a private school and resulting partition can be traced to the same force: Higherincome students are willing to pay more for school quality and are thus willing to pay more to cross subsidize higher ability students (Proposition 1). Proposition 2 shows further that between track mixing of students tends to reduce the profit gains from a purer partitioning of students.

Private school tracking, and its similarity to the allocation with competing private schools that do not track, can be illustrated with our computational model. (The calibration of the computational model is detailed in Section 4.) In particular, we compare the allocation assuming monopoly provision of private schooling with two tracks and constant scope economies to the allocation with two competing private schools that do not track. We also presume in this comparison that the public sector does not track in either case. Figure 1 plots the admission spaces in the abilityincome plane in the two equilibria, and a third case discussed below (so ignore the ****-line for the moment). The two solid lines are the boundaries separating student bodies of the public sector and the two competing private schools that do not track, with the lower left triangle those students that make up the public sector. The two dashed line are, moving from the origin to the northeast, the boundary separating the public sector students from the tracking monopolist's student body and then the monopolist's track boundary that partitions students into tracks.

As is evident in Figure 1, the boundaries separating students in the monopolist's tracks and from the public sector are barely distinguishable from the boundaries that separate students in the competing schools that do not track. It is also the case for the monopoly allocation with tracking that $\eta_{\mathrm{h}}>\eta_{1}$. Thus, from Proposition 2, there is no mixing across tracks. Since there is no mixing across 
tracks and the admission spaces to the two tracks are virtually the same as would be chosen by two competing private schools, the peer qualities experienced by students in the two tracks are virtually the same as the peer qualities experienced by students attending private schools that do not track. While the allocations under the two alternatives are very similar, profits are not. The monopolist's revenues are $33 \%$ higher than costs in the low track and $148 \%$ higher than costs in the high track. By contrast, these percentages in the two competing schools are $16 \%$ and $25 \%$ respectively. From these results, it is clear that entry by competing schools will tend to drive out private schools that engage in tracking.

It is also of interest to compare monopoly tracking to the monopoly allocation assuming no tracking (e.g., due to unacceptable stigma from low-track assignment). The public-private boundary for the monopoly allocation with no tracking is also shown in Figure 1 by the ${ }^{* * * *}$-line. Compared to the no-tracking case, tracking increases monopoly profits by $21 \%$ and monopoly admissions by 46\%. The public-private boundary shifts down and admissions rise with tracking because the monopolist offers a lower-quality product with lower peer-externality cost that is better suited to serve less-wealthy households.

The apparent substitutability of individual private school tracking for competitive provision of private schooling raises the question as to the extent to which tracking persists with free entry. Proposition 3 confirms one's intuition:

Proposition 3. If tracking by schools would be characterized by $\eta_{\mathrm{ih}}>\eta_{\mathrm{i} \ell}$ in all private schools $\mathrm{i}$ that track, then, absent strict scope economies in tracking, no private school will track in free-entry equilibrium.

The proof in the appendix formalizes the following argument. Suppose an incumbent private school were to track students. Under strict diseconomies of scope, a non-tracking entrant could serve 
students which make up one track of the incumbent school at lower cost. Moreover, the quality of schooling offered by the entrant would be the same as in the incumbent's track since the incumbent would not mix students across tracks (Proposition 2). The implied profitability of entry then precludes equilibrium with private-school tracking under strict diseconomies of scope. The entrant could further increase profits by also admitting some students from the incumbent's other track, students from whom the incumbent earns strictly positive profits. The intuition here is that the entrant undermines the monopoly pricing by a "larger incumbent." This implies further that tracking could not be sustained when constant scope economies prevail. Non-modeled institutional factors and/or administrative costs might cause private schools to consider only simple forms of tracking. In particular, tracking without any mixing and with track assignment determined strictly by ability might be all that is practical. The appendix also shows with a more general argument that does not restrict the $\eta$ 's that free entry precludes this simple form of tracking assuming no cost advantages to tracking.

Private school tracking might result if barriers to entry are present as illustrated above or if cost economies are sufficient. The evidence, however, is that private schools tend not to track (see footnote 4). ${ }^{21}$ Henceforth, we assume costs are track specific and given by (4), implying constant scope economies. This is for simplicity and is a "neutral assumption," given a lack of evidence on costs of tracking. Although we have not proved private-school tracking could never result under such circumstances (because Proposition 3 requires track-ascending $\eta$ 's), we ignore it as a possibility in the analysis that follows of market equilibrium. We find the theoretical and empirical evidence sufficiently persuasive and avoid what would be a much more difficult problem. We have also seen that if private-school tracking did result, it would likely have qualitatively similar consequences to the somewhat simpler competition among private schools and the public sector that we study.

We now turn to market properties. Recall that we assume the public sector runs two tracks 
with track boundary at exogenously determined ability B and with exogenous mixing parameter $\mathrm{m} \in[0,1)$. We examine how the results reviewed above (Section $3 \mathrm{~A}$ ) concerning the model without tracking must be modified. The same existence problem arises so we continue to examine the approximate equilibrium.

The gains from partitioning students by cross subsidization continue to imply a strict hierarchy among private schools. The high track in the public sector can, however, be of higher quality than some private schools, implying Result 1 must be modified.

Proposition 4. Equilibrium has a strict hierarchy of private schools, each of strictly higher quality than the lower track in the public sector. The quality of the higher track in the public sector can exceed that of any private school.

Proof of Proposition 4. The strict hierarchy, including the lower-track of the public sector, follows by the same argument that proves Result 1 above (Epple and Romano, 1998). To confirm the potential superiority of the upper track, observe first that the best private school must have $\theta$ bounded below $b_{\max }$ since it must be of finite size to be solvent (i.e., its $k_{h}$ is bounded above zero). The upper track of the public sector is financed by tax dollars and can have arbitrarily small $\mathrm{k}_{\mathrm{h}}$. The quality of the upper track can then be made arbitrarily close to $b_{\max }$ by setting $\mathrm{m}=0$ and $\mathrm{B}$ arbitrarily close to $b_{\max }{ }^{22}$

The proof shows the upper track can be of higher quality than every private school. Figure 7 provides an example, discussed further below, from our computational analysis having the upper track of higher quality than some but not all private schools. It also demonstrates that such an outcome can result for non-extreme B and interior $\mathrm{m}$.

The pricing properties collected in Result 2 carry over as does the income-stratification 
property of Result 3, with analogous proofs. Public-school tracking can, however, disrupt the simple ability stratification that is typical without tracking.

Proposition 5. For equilibrium with weakly ascending $\eta$ 's across private schools (i.e., $\eta_{1} \leq \eta_{2} \leq \ldots \leq \eta_{\mathrm{n}}$ ), stratification by ability holds among students that attend private schools or the lower public school track, but not generally when upper-track, public-school students are included.

The proof of Result 3b (Epple and Romano, 1998) confirms SBA for the first group of students in Proposition 5. The reversal of SBA can occur when the upper track is of higher quality than a private school as illustrated again by Figure 7. For students with income below $\$ 50,000$ or so, observe that school quality declines with ability as the public-sector, private-sector boundary locus is crossed. The higher-ability students choose the weaker private school over the free high track in the public sector because they receive a fellowship (negative tuition) of sufficient magnitude.

Any of the figures with tracking depict a general and more fundamental property of the equilibrium partition with tracking.

Proposition 6. The boundary locus between the public and private sectors is discontinuous at the track boundary B, where there is a discrete increase in household income as ability rises.

The proof is trivial. The discrete jump in public school quality as ability rises above the track boundary implies discretely higher income is necessary for a household to be indifferent between the reduced quality premium to private-sector schooling.

The graphic counterpart of Proposition 6 is the jagged upper edge of the public-sector, private-sector boundary locus, e.g. in Figures $2 b-2 d$. This conforms to the main allocative effect of tracking. Relative to no tracking (see Figure 2a), public-sector quality declines to those who only 
qualify for the lower track and the public-sector, private-sector boundary locus shifts toward the origin for $\mathrm{b}<\mathrm{B}$. The reverse holds for ability levels above the track boundary. The introduction of tracking renders the public sector more effective in competing for higher-ability students who qualify for the upper track, but less effective in attracting lower-ability students. Among non-qualifying, lower-ability students, it is relatively higher-income types that tracking induces to exit the public sector. Among higher-ability students that qualify for the upper track, it is relatively higher-income types that tracking keeps from attending private schools. These tend to produce an allocation having positive correlation between income and the track hierarchy in public schools, whether or not income and student ability are positively correlated. All these effects are intensified as the mixing parameter declines. Quantification of these effects is explored in Section 4.

We now consider briefly the normative implications of tracking. First, treat school quality as a consumption good. Result 4 a continues to apply since it regards a fully private equilibrium. The public sector with tracking will not produce an efficient allocation as in Result $4 \mathrm{~b}$. The effective track tuitions, zero to track qualifiers and infinity to non-qualifiers, fail to reflect the social cost of admission.

We examine the effects of tracking on the distributions of compensating variation and achievement computationally. We can anticipate that qualification for the high track will tend to cause gains in both measures for such students and the reverse for non-qualification. But "general equilibrium effects" preclude simple definitive theoretical results. For example, a student who qualifies for the high track could experience a decline in achievement due to tracking. Consider the student initially in private school who saves tuition costs by switching to a public school improved by tracking, but of lower quality than the private alternative (which would have also changed some in quality). One other primary effect of tracking warrants mention here. Tracking will increase the scarcity of ability for use in the private sector, tending to bid up its market value. The positive 
counterpart will be higher tuition discounts to ability, i.e., higher private-sector $\eta$ 's.

C. A Generalized Peer Group Measure. A generalization of the model permits Rothschild-Stiglitz (1970) variability in student ability among classmates to reduce educational quality. ${ }^{23}$ Proponents of tracking tout the virtues of intellectual homogeneity among classmates for curriculum specialization. This can be captured by having school quality equal to the mean of an increasing, differentiable, and concave function of student ability, denoted $\mathrm{g}(\mathrm{b})$. Track or school quality is then given by the analogue of (1):

$$
\theta_{\mathrm{i}}=(1-\mathrm{m}) \overline{\mathrm{g}_{\mathrm{i}}}+\mathrm{mg}, \mathrm{i} \in\{\ell, \mathrm{h}\},
$$

where $\bar{g}_{\mathrm{i}}$ is the mean of $\mathrm{g}(\mathrm{b})$ in track $\mathrm{i}$ and $\bar{g}$ the mean in the school. For given track and school mean abilities, quality then declines as Rothschild-Stiglitz variability rises when $\mathrm{g}(\mathrm{b})$ is strictly concave.

It is shown in the Appendix that the "Results" and "Propositions" above continue to hold with trivial modifications. The underlying logic is that the relevant distribution of student types becomes that over $(\mathrm{y}, \mathrm{g}(\mathrm{b}))$, rather than $(\mathrm{y}, \mathrm{b})$, so qualitative results are unaffected. Quantitative effects could, however, be important. ${ }^{24}$ Hence, we examine this generalization further below computationally.

\section{Computational Model and Results}

A computational model allows us to flesh out the effects of tracking on the public school sector, and the effect of public school tracking on private schools' clientele and quality. When possible we have calibrated the computational model to existing empirical evidence. In interpreting our results, however, it is important to keep in mind that empirical evidence is limited on some important parameters. 
A. Specification and Calibration. We adopt the computational model in Epple and Romano (1998), and extend it to include public school tracking. We briefly summarize the former's calibration here and then go on to discuss the calibration of the tracking parameters. The computational model entails a choice of joint density function for income and ability, utility and achievement functions, and the cost function for education.

Income and ability follow a joint lognormal distribution: $\left[\begin{array}{l}\operatorname{Ln}(b) \\ \operatorname{Ln}(y)\end{array}\right]$ is distributed bi-variate normal with mean $\left[\begin{array}{l}\mu_{b} \\ \mu_{y}\end{array}\right]$ and covariance matrix $\left[\begin{array}{cc}\sigma_{b}^{2} & \rho \sigma_{b} \sigma_{y} \\ \rho \sigma_{b} \sigma_{y} & \sigma_{y}^{2}\end{array}\right]$. Calibrating the marginal distribution of income to mean $(\$ 36,250)$ and median $(\$ 28,906)$ income in 1989 yields $\mu_{\mathrm{y}}=3.36$ and $\sigma_{\mathrm{y}}=.68$, where we henceforth measure income in thousands.

To calibrate the ability distribution, we assume the ability distribution to be a primitive, i.e., independent of policy changes. We further assume that future earnings are linear in normed achievements, $a_{N}$. The latter is obtained by raising the achievement function we adopt, $a=\theta^{\gamma} b^{\beta}$, to the power $1 / \beta$ and multiplying by a constant: $a_{N} \equiv \Lambda_{0} \theta^{\frac{\gamma}{\beta}}$ b. Hence, normed achievement is measured in the same units as ability, and both are measured in dollars. Results from Henderson, Mieszkowski, and Sauvageau (1977) imply an elasticity of achievement with respect to peer ability 30 percent as large as the elasticity with respect to own ability: $\frac{\gamma}{\beta}=.3$. We conservatively set $\frac{\gamma}{\beta}=.2$. Parameters for the ability distribution are then chosen to give rise to an approximate steady-state equilibrium when there is no tracking. That is, the distribution of normed achievement in each generation (approximately) replicates the distribution of income of the parent generation. A final step adjusts for the difference between ratios of employed workers per household (1.3 in 1990 ) and students per household (.5 in 1990). The outcome of this calibration process is $\mu_{\mathrm{b}}=2.42$ and $\sigma_{b}=.61$. For our benchmark case, we set $\rho=0$ and then examine the effects of increasing $\rho$ to $.4 .^{25}$ This completes the calibration of $\mathrm{f}(\mathrm{b}, \mathrm{y})$.

The combined utility-achievement function is assumed Cobb-Douglas (recall (2)). For 
calibration and in the main analysis, we assume that quality is given by (1), and we consider the extension in (10) last. The share of disposable personal income spent on education in the U.S. is approximately.056. Parameter $\gamma$ is chosen to yield the observed expenditure share if school quality could be purchased at a constant price per unit of quality, implying $\gamma=.06$. This and $\frac{\gamma}{\beta}=.2$ from above yield the calibrated utility function $U=\left(y_{t}-p\right) \theta^{.06} b^{3}$. We also examine sensitivity of our results to the value of $\gamma$.

We assume constant scope economies in tracking and measure a school's or track's size, $\mathrm{k}$ $\in[0,1]$, as the proportion of the population's households (or students) using the school. The cost function for private schools and for each track in a public school is assumed quadratic in $\mathrm{k}, \mathrm{F}+\mathrm{V}(\mathrm{k})$ $=\mathrm{C}_{0}+\mathrm{C}_{1} \cdot \mathrm{k}+\mathrm{C}_{2} \cdot \mathrm{k}^{2}$. Expenditure per student in public schools in 1988 was $\$ 4,222$ (Statistical Abstract, 1991, p. 434), and there was approximately $1 / 2$ students per household (Statistical Abstract, 1992, p. 46 and p. 136). Thus, educational expenditure per household was approximately $\$ 2,100$, and the cost function parameters were chosen such that average cost reaches a minimum at this value (and to satisfy second-order conditions). Specifically, we use the following track/school cost function: $\mathrm{F}+\mathrm{V}(\mathrm{k})=3.8+1,300 \cdot \mathrm{k}+42,103.95 \cdot \mathrm{k}^{2}$. This function yields a minimum average cost per household of $\$ 2,100$ when $\mathrm{k}^{*}$ (efficient scale) $=.9$ percent of the student population, implying each private school serves about 1 percent of the population. ${ }^{26,27}$

Two parameters, the public school track boundary, B, and the mixing parameter, m, characterize tracking in our model. Data presented in Gamoran (1992), for example, indicates that there is typically some mixing between tracks (see footnote 3 ). Thus, we chose a mixing parameter of .25 for our benchmark calibration to allow a moderate amount of mixing in our benchmark equilibrium. We then chose the benchmark track boundary B, as the value such that the percentage of students in the high track in our benchmark equilibrium equals $33 \%$, close to the average value of $30 \%$ reported by Gamoran (1992). The resulting value of B equals 14.4 and is roughly at the 65 th 
percentile of our ability distribution.

B. Computing Equilibrium. Several factors that complicate the computation of equilibrium are discussed here. Recall that the existence problem leads us to examine an epsilon-competitive equilibrium, so a value of epsilon must be specified. We chose, of course, the minimum value that is consistent with the comparative statics we perform. This value of epsilon is 1.61 and equals approximately 8.5 percent of total school cost at the efficient scale.

Consider the determination of boundary loci. Let an indifference locus between two private schools consist of the set of types $(b, y)$ indifferent between them when tuition at each school equals effective marginal cost. Let an indifference locus between a private school and a public school track consist of indifferent students who qualify for the track while facing zero tuition at public school and, again, tuition equal to effective marginal cost at the private school. When there are no intersections of the indifference loci in the support of $\mathrm{f}(\mathrm{b}, \mathrm{y})$, boundary loci are simply determined, equal to the subset of indifference loci between schools/tracks of adjacent quality. This occurs, e.g., in our equilibrium with no tracking (Figure 2a). However, the cases of tracking typically result in crossing of indifference loci which is seen to be manifest in kinks in the boundary loci (e.g., the other panels of Figure 2). This complicates the characterization of admission spaces. In the appendix, we demonstrate how admission spaces and boundary loci are then determined.

To compute the price function and profit of a private school, it is necessary to determine the utility each student in that school could obtain in the student's next best alternative school. While an analytic characterization is easily obtained, this proves to be an exceedingly difficult computational problem when indifference loci of schools cross. Hence, we approximate by characterizing the equilibrium obtained when schools set price equal to effective marginal cost, i.e., do not price discriminate by income. We know that this is the limiting outcome as private school 
size approaches zero. In the benchmark calibration of the computational model, each private school serves less than one percent of the student population. Hence, our schools are small, and this approximation is then likely to be a good one. ${ }^{28}$

Last, our calculation of aggregate public school costs deviates slightly from the above theoretical model. We allow public schools to run multiple high and/or low tracks, if they can lower cost by doing so. ${ }^{29}$ We do this because it reduces the effect on costs in the public sector of varying the track boundary, by permitting schools to come closer in maintaining track sizes near $\mathrm{k}^{*}$. All our theoretical results are consistent with this alternative.

C. Results. Varying the mixing parameter, $\mathrm{m}$, proves to be quite useful in assessing the effects of tracking. Figure 2 shows how mixing of students across tracks affects the number of schools and the distribution of students by income and ability across schools, holding constant $\mathrm{B}=$ 14.4. Figure $2 \mathrm{a}$ is the equilibrium when there is no tracking $(\mathrm{m}=1)$; Figure $2 \mathrm{~d}$ is the equilibrium with complete segregation of students by track $(\mathrm{m}=0)$. Panels $\mathrm{b}$ and $\mathrm{c}$ are for intermediate mixing levels, with the latter our benchmark case. Reducing mixing across tracks increases the attractiveness of the high track and reduces the attractiveness of the low track. As a result, the number of students in the high track increases as mixing is reduced, and the number of students in the low track decreases.

These effects are summarized in Figure 3 which shows the boundary loci between the public and private sectors for three mixing levels. As mixing is reduced, high-income households with lowability students (i.e., students who do not qualify for the high track) switch to private schools, shifting the public-private boundary downward in this region (i.e., to the left of the track boundary). For students qualifying for the high track, reduced mixing increases peer quality in the public school. This in turn draws students into the high public school track, shifting the public-private boundary 
outward in this region. The exception are some very low income students who are drawn into the private sector by an increased ability premium as discussed further below.

One might expect that tracking tends to increase the size of the public sector relative to the private sector. This proves to be the case in our calibrated model. As Figure 2 illustrates, there are 9 private schools when there is no public school tracking. Tracking with a mixing parameter of .75 results in one private school exiting. Further reducing mixing to .25 results in exit by an additional private school. The effect is not monotonic for the entire range of mixing parameters, however. Further reduction of mixing across public tracks results in entry of a private school. High-income families with low-ability students become increasingly desperate to leave the public sector as the quality of the low track is reduced by limited mixing.

We find that public sector attendance is maximized by permitting some mixing, with students attending mixed classes about 40 percent of the time. The effect of mixing on overall public schools attendance is moderate, however. Setting $\mathrm{m}=0(\mathrm{~m}=1)$ reduces public sector attendance by about two (one) percent relative to the attendance achieved at $\mathrm{m}=.40$. As shown in Figure 3, attendance in the two tracks is more sensitive to mixing. Attendance in the lower track rises by about $3.5 \%$ as the mixing parameter is increased from 0 to 1 , and attendance in the upper track declines by about $10 \%$.

Figure 4 shows the effects of mixing on mean public school ability overall (upper panel) and peer ability in the two tracks (lower panel) measured as a percent of mean population ability for benchmark $\gamma=.06$ and for $\gamma=.08$. Public school mean ability is below the population mean in all cases. As shown in the upper panel, the mean ability reaches its maximum when the tracks are the most isolated from each other. This follows from Figure 3 since increased mixing increases public school attendance by low-ability students and reduces attendance by high-ability students. Note that a public school objective function that places weight on both attendance and overall mean student 
ability could lead to a mixing choice between 0 and .4 in our calibrated model.

When there is mixing across tracks, mean ability of the public school student body is one component of a track's quality, and mean ability within the track is the other. As mixing is increased, the quality of the school student body has an increasingly large weight in determining the peer quality of each track (see (3)). This is illustrated in the lower panel of Figure 4 for benchmark $\gamma=$ .06 and also for higher $\gamma=.08$. At the benchmark equilibrium of $\mathrm{m}=.25$, the high track students have a mean ability above the mean population ability. In the limit with complete mixing, the peer qualities of the two tracks are identical.

School qualities, school/track sizes, and private-school tuition discounts to a one-standard deviation increase in ability are shown for three mixing parameters in Table 1. These correspond to panels (a), (c), and (d) of Figure 2. The results in Table 1 show that the high track of the public school is of lower peer quality than the private schools for these parameter values. However, as we demonstrate later, there are parameter values for which the high public track is of higher quality than some private schools. Comparing the columns of discounts to ability in Table 1 also reveals that the shadow prices of ability (i.e., the $\eta$ 's) in private schools rise when tracking is introduced. Taking private school 3 in the three cases for example, $\eta_{3}$ rises from .130 in the case with no tracking, to .149 when mixing is 25 percent, to .153 when there is no mixing. These correspond to tuition discounts for a one standard deviation increase in ability of $\$ 2,365, \$ 2,710$, and $\$ 2,783$ respectively. Thus, private schools must pay a higher premium to attract more able students from the public schools when there is tracking because the high track in the public school provides free access to a high quality peer group.

Figure 5 mirrors the quality change of the tracks shown in Figure 4. As mixing increases, per student normed achievement, or equivalently, average future earnings, decreases for high track students and increases for low track students. Figure 5 also reveals that overall per student public 
school achievement is little affected by the change in tracking. Achievement gains accruing to high track students are counterbalanced by losses to low track students. Per student achievement in the entire population, shown by the "total achievement" curve is likewise relatively flat. The figure also shows total achievement for $\gamma=.08$, which is barely distinguishable from the benchmark case with $\gamma=.06$. This graph emphasizes that, for the simulations we have done, the effects of tracking are largely distributional with little effect on aggregate achievement.

The distributional effects of tracking on student welfare are pictured in the upper panel of Figure 6. Welfare change is estimated as the compensating variation associated with going from no tracking to our benchmark equilibrium $(\mathrm{B}=14.4 ; \mathrm{m}=.25) .{ }^{30}$ The solid lines in the upper panel are the boundaries between the public and private sectors with and without tracking (i.e., boundaries between private schools are suppressed), which delineate seven areas. The top panel also shows several contours of the change in welfare as a percentage of income. For example, the curve labeled $0 \%$ in the right portion of the diagram is the locus of types whose welfare is unaffected by the introduction of tracking. Consider first students who qualify only for the low track. All such students have a loss in welfare when tracking is instituted. Students that remain in the public school are the worst off (area 1). The Cobb-Douglas specification leads the welfare change as a percent of income to be the same for all students who attend public sector schools both before and after the introduction of tracking. For each ability, the welfare decrease is smaller for students who choose private school in the equilibrium with tracking. Some high income students switch from public to private school when tracking is introduced (area 2). The deterioration of the quality of the public sector for which they are eligible leads them to switch to a private school, where they must pay tuition. High income students that were in private schools before and after tracking are also worse off (area 3). As we noted earlier in our discussion of Table 1, introduction of tracking increases the attractiveness of the public schools to high-ability students. As a result, private schools must give 
higher tuition discounts to attract able students to the private sector. This in turn leads to higher tuition payments by low-ability students in the private sector, reducing their welfare.

Turning to the high track in the upper panel of Figure 6, we see that the majority of students who qualify for the high track are better off with tracking, this group comprised of all those below the $0 \%$ contour. Most of these students experience welfare gains between 0 and 5 percent. Those in the lower right of the admission space in region 7 have greater stipends while remaining in the private schools. Students lying below the 5 percent welfare locus in the top panel of Figure 6, including some from both regions 5 and 7 , are the biggest percentage gainers from tracking. While some of them in region 7 experience achievement losses (as discussed further below), their financial gains more than offset losses in school quality that they experience from the introduction of tracking.

Among those who qualify for the high track, households above the $0 \%$ contour are worse off with tracking. All of these students were in private schools in the no-tracking equilibrium. The more intense competition for high-ability students that arises with tracking induces the schools with highest ability students to shrink in size. Shrinking allows a school to increase peer quality at the margin by eliminating students near the lower boundary of the school's admission space. The increased average tuition resulting from operating at a less cost efficient scale means tuition rises for the bulk of households served by those schools. This adversely impacts the relatively wealthy households served by the highest quality private schools. Some of these households switch to the high track in the public school, but are nonetheless worse off than in the private school they attended in the absence of tracking.

The lower panel of Figure 6 illustrates the achievement changes due to tracking analogously to the upper panel. It shows the same seven areas but leaves off iso-achievement contours. These contours have numerous jumps due to small changes in private school qualities and their inclusion would cloud the picture. Consider first those who qualify only for the low track. Those in private 
school with and without tracking (area 1) experience the same percentage achievement loss of about 6.8 percent. Those who switch into the private sector due to tracking (area 2) gain quite substantially in achievement, but are worse off as we have seen. Those in the private sector with and without tracking (area 3) experience small and variable changes in achievement as private school qualities and their own choices among them vary.

Next consider those who qualify for the high track. Here, the students who are in the public school when there is no tracking are the big gainers in achievement. Of those, the set who switch to private school (area 5) are the biggest achievement gainers. Students drawn into the public sector by tracking experience substantial achievement losses (area 6), but we have seen that most of them are better off. Students in private schools before and after tracking are affected similarly in achievement to those who do not qualify for the upper track.

Figure 7 depicts the equilibrium allocation under a more selective tracking policy: with $\mathrm{m}=.25$, again, but with track boundary at the 95 th percentile of ability as in some "gifted programs." Perhaps most interesting is that the upper track is of higher quality than four of the six private schools. All students who qualify for the upper track but attend a lower-quality private school do so because they are given fellowships. The fellowships are financed within these schools by relatively wealthy students who fail to qualify for the upper track and are willing to pay substantially to attend school with high-ability students. The upward sloping portion of the private-sector, publicsector boundary at the lower right edge of the upper track is implied by income stratification.

Thus far we have employed a joint distribution on income and ability with correlation coefficient equal to zero. Perhaps surprisingly, most of the equilibrium properties are largely unaffected by varying $\rho$ within the above-identified range $[0,4]$ (see footnote 23 ). As examples, if $\rho$ is increased from 0 to .4 with other parameters at the benchmark values, there is no change in the number of private schools and the public sector attendance rises negligibly from 92.5 percent of the 
population to 92.6 percent.

An exception is the within track income distributions in the public sector. Table 2 shows these distributions by income quartiles in the cases of $\rho=0$ and .4, as well as Rees, et. al.'s (1996) estimates of comparable distributions. The latter attests to the "stylized fact" of positive correlation between income and track placement. Even if $\rho=0$, our model of tracking predicts a positive correlation although weakly. But this reflects a significant reallocation: One can infer from panel a of Figure 2 that the pattern of stochastic dominance of these income distributions within ability groups in public schools would be reversed without tracking. Put differently, our model with $\rho=$ 0 predicts a negative correlation between income and ability among students in public schools without tracking, which tracking will tend to offset. This is because private schools attract a mixture of higher-income, lower-ability students and lower-income, higher-ability students when competing with an untracked public sector. Tracking by public schools draws "back" relatively higher-income, higher-ability students who qualify for the high track while pushing out relatively higher-income, lower-ability students who fail to qualify. Hence, tracking can induce the observed pattern of socioeconomic differences across tracks as an equilibrium outcome independent of positive correlation between ability and income in the population.

Increasing $\rho$ to .4 results in track income distributions that are very close to the corresponding distributions in Rees, et.al. Because teachers classified students into four, rather than two, groups in the data employed by Rees, et.al., our simpler model cannot be perfectly matched to this data (see the footnote to Table 2). We do not place undue significance on the closeness of fit. We interpret these results as lending some support to our model and as indicating that positive correlation of household income and student ability is of some importance in explaining income distribution by track.

Last, we examine equilibrium effects of gains from reduced variability of students ability in 
classes by implementing the generalized peer measure discussed above in Section 3C. We let: $\mathrm{g}(\mathrm{b})=\Psi_{0} \mathrm{~b}^{\psi_{1}}$, with $\Psi_{0}>0$ and $\psi_{1} \in(0,1]$. Hence, for $\psi_{1}<1, \mathrm{~g}(\mathrm{~b})$ is concave and school quality declines with increases in the Rothschild-Stiglitz variability of ability in the school. The case of $\psi_{0}=\psi_{1}=1$ is that studied to this point. We lower $\psi_{1}$ from 1 to investigate the equilibrium effects of variability. When this is done, we routinely adjust $\psi_{0}$ so that $\mathrm{E}[\mathrm{g}(\mathrm{b})]$ is constant in the population. This is a normalization to preserve the relevance of school quality in the model. ${ }^{31}$

In the main experiment, we let $\psi_{1}$ decline from 1 with benchmark values of $\mathrm{m}=.25$ and $\mathrm{B}$ such that one-third of public-school students are in the upper track. We find that the private sector shrinks as $\psi_{1}$ declines. Once $\psi_{1}=.6$ for example, only two private schools remain serving 1.7 percent of the population. We believe that the central trade off is this: Private schools face no institutional constraints, i.e., can group students as they please, while public schools have their admission policy dictated. This would seem to imply that private schools have the advantage over public schools of being able to reduce variability in student ability as $\psi_{1}$ declines. However, the profitability of private schools depends on the cross subsidization from relatively higher-income and lower-ability types to relatively lower-income and higher-ability types that they engender. Even when there is complete mixing in the public sector, the variability in ability of private-school peer groups is much higher than in public schools (see Figure 3A in Epple and Romano, 1998, p. 50). Decreasing $\Psi_{1}$ then markedly curtails a private school's ability to generate surplus. This economic constraint dominates their institutional advantage, and the private sector contracts as $\psi_{1}$ declines. We find this for all values of the mixing parameter.

Figure 8 shows (normed) mean achievement measures as $\psi_{1}$ is varied, again for benchmark values of other parameters. While achievement in the population is essentially invariant, mean achievement in both tracks of the public sector and the public sector overall rises as $\psi_{1}$ declines. Given constant population achievement and the net relative advantage of the public sector that we 
find, this is then to be expected. We emphasize, however, that we consider our computational findings on the interaction of peer-group ability variability and relative public-school versus privateschool performance to be preliminary. For example, private schools might more easily reduce ability variability if they can provide higher quality educational inputs like teacher skill, something that our model does not incorporate.

\section{Concluding Remarks.}

Our goal in this paper has been to investigate the effects of tracking on the composition of public and private schools and to study the implications for student achievement and household welfare.

Our theoretical results reveal that private schools have limited incentive to engage in tracking. Private schools can select students and set tuition levels that reflect differences in student abilities. Given these mechanisms for determining the composition of the school student body, competition among private schools leaves them with little if any incentive to separate students into subgroups within schools.

Public schools, by contrast, have few direct mechanisms to control student body composition. Our computational results reveal that tracking can significantly affect public school composition. By grouping students by ability, a public school can offer a relatively high quality peer group to more able students, attracting more such students to the school. At the same time, less able students find that tracking reduces the quality of their public school peer group. This in turn induces some such students, the relatively more able and affluent from within the low track, to choose private education. These student responses to tracking lead socioeconomic status to be a predictor of track placement in public schools as in reality.

Our computational results suggest that some degree of tracking can both increase the size of 
the public school sector and its average quality. Whether this is a socially desirable outcome is, of course, a separate issue. Resolution of this question involves distributional tradeoffs. Our analysis provides insights into the nature of those tradeoffs. Not surprisingly, tracking generally reduces the welfare of less able students, particularly the less affluent. Tracking generally enhances the welfare of more able students, particularly the less affluent. Thus, the distributional tradeoffs associated with tracking are primarily tradeoffs across ability groups rather than across income groups.

Our model yields several testing predictions regarding tracking. Not surprisingly, tracking increases achievement of students in the public school who qualify for the high track and reduces achievement of those who do not qualify for the high track. This in turn leads to an increase in public school enrollment among students who qualify for the high track and a reduction in enrollment among students who do not. Because the students who switch sectors with tracking are relatively higher income, the correlation between income and ability in public schools that track is predicted to be higher than in those that do not. Our simulations suggest that the net effect on attendance from introduction of tracking is to increase relative size of the public sector. By making it harder to attract higher-ability students into private schools, tracking increases the premium to ability in private schools. When there is public school tracking, some private schools may be of lower quality than the high public track, particularly if the public track is highly selective (gifted programs). Finally, our model predicts that tracking should be little used in private schools where barriers to entry are low.

Challenging identification issues arise in empirical work when peer effects are present (Manski, 1993; Moffitt, forthcoming). Our analysis emphasizes that track peer quality is endogenous because the introduction of tracking tends to increase attendance of higher-ability students and reduce attendance of lower-ability students. Thus, the identification issues raised by Manski and Moffitt will typically arise in studying the effects of tracking. Our work also emphasizes the 
importance of measuring peer effects at the classroom rather than school level. Suppose tracking is present but is neglected when calculating peer characteristics. Both peer effects and the effects of tracking may be underestimated as a result since our computational analysis indicates that the effect of tracking on average achievement may be small even though the effect on students within tracks may be substantial.

A shortcoming of our analysis is a failure to recognize the heterogeneity of public schools deriving from neighborhood schooling policies (i.e., exclusive territories of public schools) and Tiebout sorting. Our model is as though there is freedom of choice among public schools. Epple and Romano (1995) examine neighborhood schooling versus choice in a model that incorporates peer effects in education, but without any ability grouping or private sector. Merging this research is of interest. Perhaps tracking can permit poorer neighborhoods to retain more higher-ability students who would otherwise migrate for better schooling. ${ }^{32}$ 


\section{References}

Argys, Laura M., Rees, Danile I. and Dominic J. Brewer, "Detracking America's Schools: Equity at Zero Cost?" Journal of Policy Analysis and Management, Vol. 15, No. 4, Fall 1996, 623-645.

Science," mimeo, 1997.

Arnott, Richard and John Rowse, "Peer Group Effects and Educational Attainment," Journal of Public Economics, Vol. 32, No. 3, April 1987. 287-305.

Caucutt, Elizabeth, “Education Policy When There Are Peer Group Effects," University of Rochester Working Paper, 1998

Coleman, James and Thomas Hoffer, Public and Private High Schools, New York, Basic Books, Inc., 1987.

Epple, Dennis and Richard Romano, "Competition Between Private and Public Schools, Vouchers, and Peer Group Effects," American Economic Review, March 1998, 62(1), pp. 33-62.

, "Public School Choice and Finance Policies, Neighborhood Formation, and the Distribution of Educational Benefits," University of Florida Working Paper, July 1995.

, "Educational Vouchers and Cream Skimming," Carnegie Mellon University Working Paper, 1999.

Figlio, David N. and Marianne E. Page, "School Choice and the Distributional Effects of Ability Tracking: Does Separation Increase Equality?” University of Florida Working Paper, March 1999.

Gamoran, Adam, "The Variable Effects of High School Tracking, American Sociological Review, Vol. 57 (December 1992), 812-828.

, "Curriculum Standardization and Equality of Opportunity in Scottish Secondary Education: 1984-90," Sociology of Education, Vol. 69 (January 1996), 1-21.

Haveman, Robert H. and Barbara L. Wolfe, "Schooling and Economic Well-Being: The Role of Nonmarket Effects," Journal of Human Resources, Vol. 19, No. 3 (Summer 1984), 377407.

Henderson, V., P. Mieszkowski, and Y. Sauvageau, "Peer Group Effects in Educational Production Function," Journal of Public Economics, 10, 1978, 97-106.

Kenny, Lawrence, "Economies of Scale in Schooling," Economics of Education Review, 2, 1 (Winter 1982), 1-24. 
Manski, Charles, "Identification of Endogenous Social Effects: The Reflection Problem," Review of Economic Studies, 1993, 60, 531-542.

Moffitt, Robert, "Policy Interventions, Low-Level Equilibria and Social Interactions," forthcoming in Social Dynamics (Steven Durlauf and Peyton Young, eds.)

Moreland, Richard L. and John M. Levine, "The Composition of Small Groups," in E.J. Lawler, B. Markovsky, C. Ridgeway, and H. Walker, eds., Advances in Group Processes, Vol. 9., Greenwhich, CT: JAI Press, 1992.

National Center For Education Statistics, Private Schools in the United States: A Statistical Profile, 1990-91, U.S. Department of Education, Office of Educational Research and Improvement, January 1995.

Nechyba, Thomas J., "School Finance Induced Migration and Stratification Patterns: The Impact of Private School Vouchers," Journal of Public Economic Theory, 1999, 1(1), pp. 5-50.

Oakes, Jeannie, Gamoran, Adam, and Reba N. Page, "Curriculum Differentiation: Opportunities, Outcomes, and Meanings," Chapter 21 in Handbook Of Research On Curriculum, Philip W. Jackson, ed., New York: Macmillan Publishing, 1992, 570-607.

Rees, Daniel I., Argys, Laura M. and Dominic J. Brewer, "Tracking in the United States: Descriptive Statistics from NELS," Economics of Education Review, Vol. 15, No. 1, 1996, 83-89.

Rothschild, M. and J. Stiglitz, “Increasing Risk I: A Definition,” Journal of Economic Theory, 1970, 2, 225-43.

Scotchmer, Suzanne, "Public Goods and the Invisible Hand," in J. Quigley and E. Smolensky, eds., Modern Public Finance, Cambridge, MA: Harvard University Press, 1994.

, "On Price-Taking Equilibria in Club Economies with Nonanonymous Crowding, Journal of Public Economics, June 1997, 65(1), pp. 75-87.

, and Myrna H. Wooders, "Competitive Equilibrium and the Core in Club Economics with Nonanonymous Crowding," Journal of Public Economics, 34 (1987), 159-173.

Solon, Gary, "Intergenerational Income Mobility in the U.S.," American Economic Review, June 1992, Vol. 82, No. 3, 393-409.

Sorensen, Aagee B., "Organizational Differentiation of Students and Educational Opportunity," Sociology of Education, Vol. 43 (fall 1970), 355-376.

Summers, A. and B. Wolfe, "Do Schools Make a Difference?," American Economic Review, 67, 4 (September 1977), 639-652.

Suro, Mary Davis, "Selecting the Smart Set," New York Times: Education Life, Section 4A, November 1, 1992, p. 18. 
Zimmerman, David J., "Regression Toward Mediocrity in Economic Stature," American Economic Review, Vol. 82, No. 3, June 1992, 409-429. 


\section{Figure 1:}

COMPARISON OF TRACKAND SCHOOL BOUNDARIES UNDER WONOPOLY TO SCHOOL BOUNDARIES UNDER COWPETITION

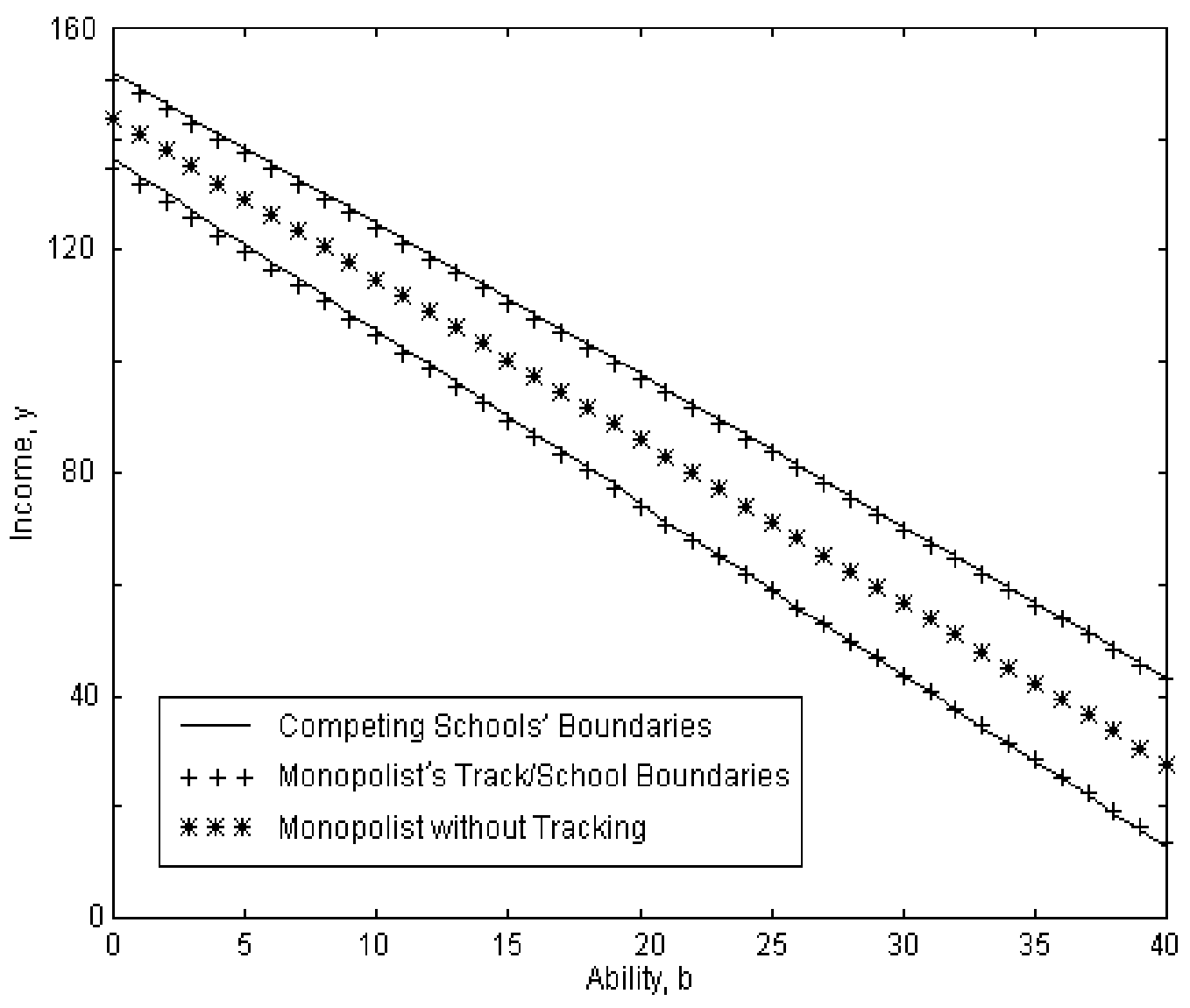



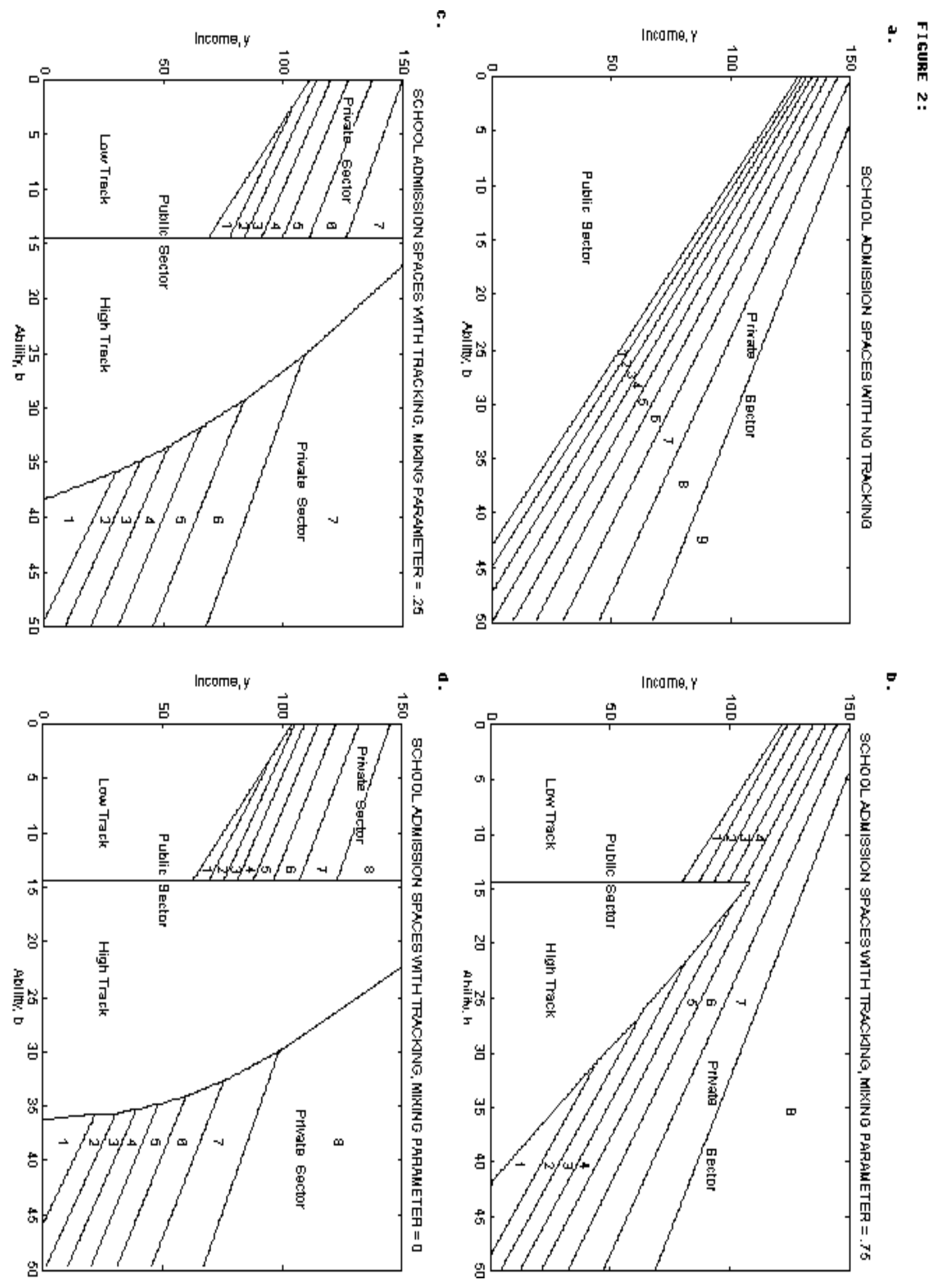


\section{Figure 3:}

SCHOOL ADMISSION SPACES FOR THE LOW \& HIGH TRACKG FOR DIFFERENT MIXING PARAMETERG

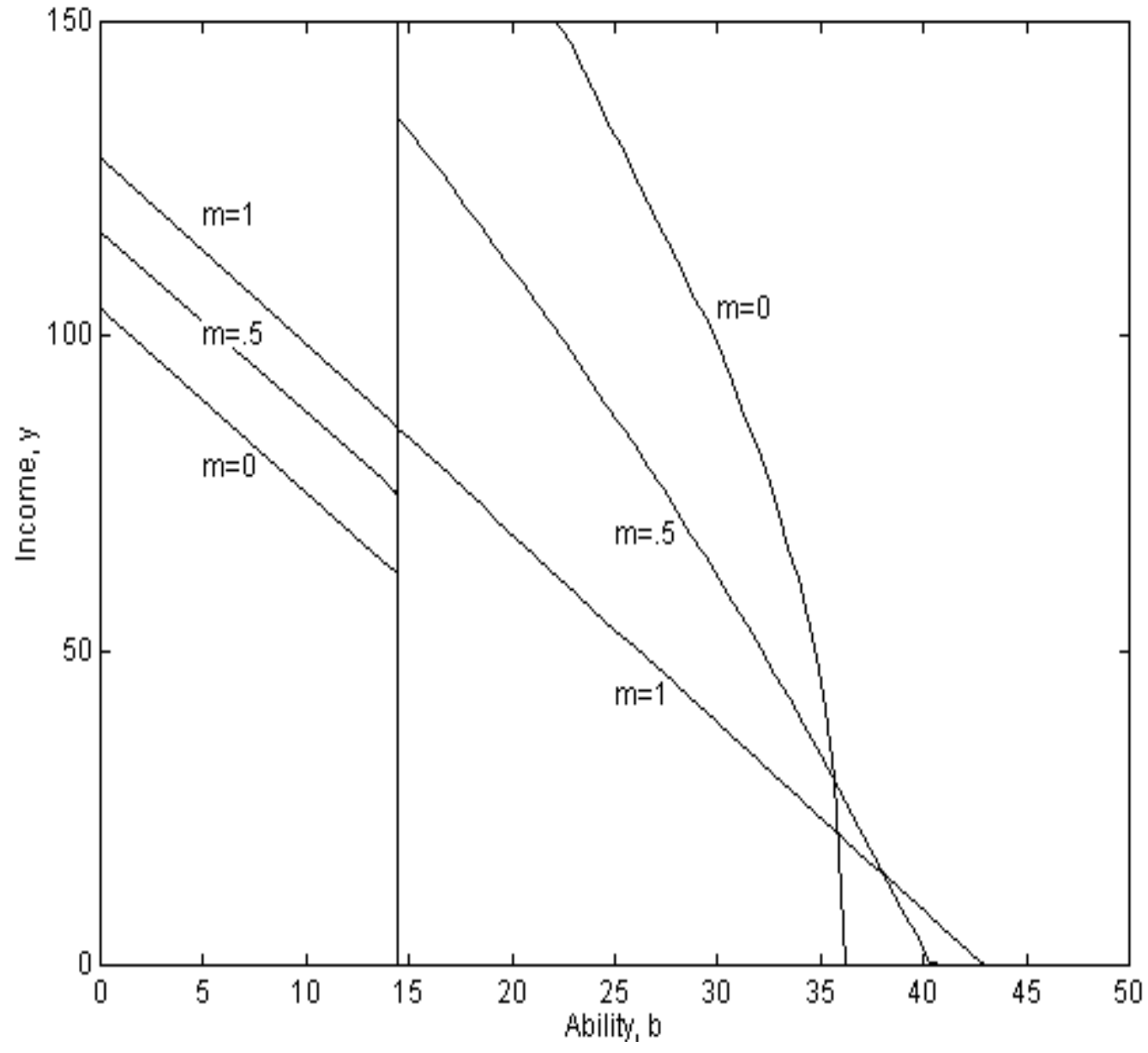




\section{Figure 4:}

AVERAGE FUELIC SCHOOL ABILITY AG \% OF POPULATION ABILITY FOR EACH MIXING LEVEL, B=14.4

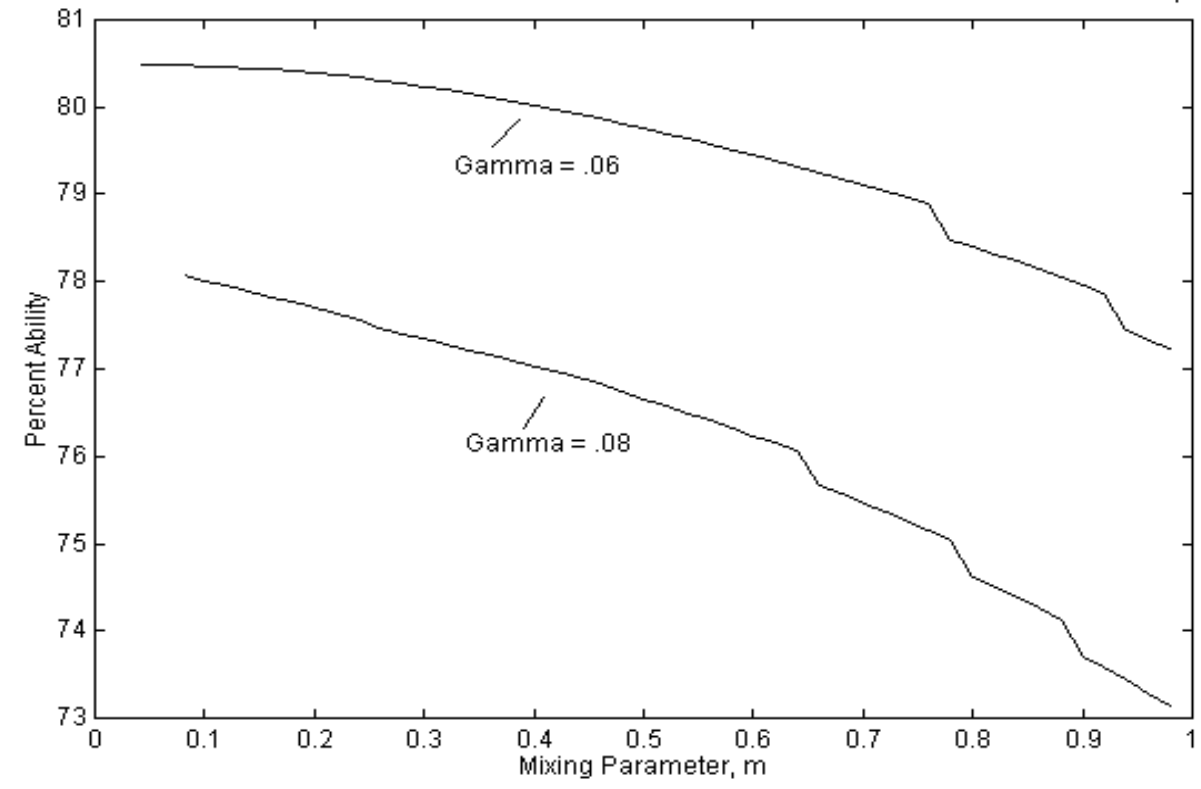

PEER QUALITY IN EACH TRACKAG $\%$ OF POPULATION PEER QUALITY FOR EACH MIXING LEVEL, E=14.4

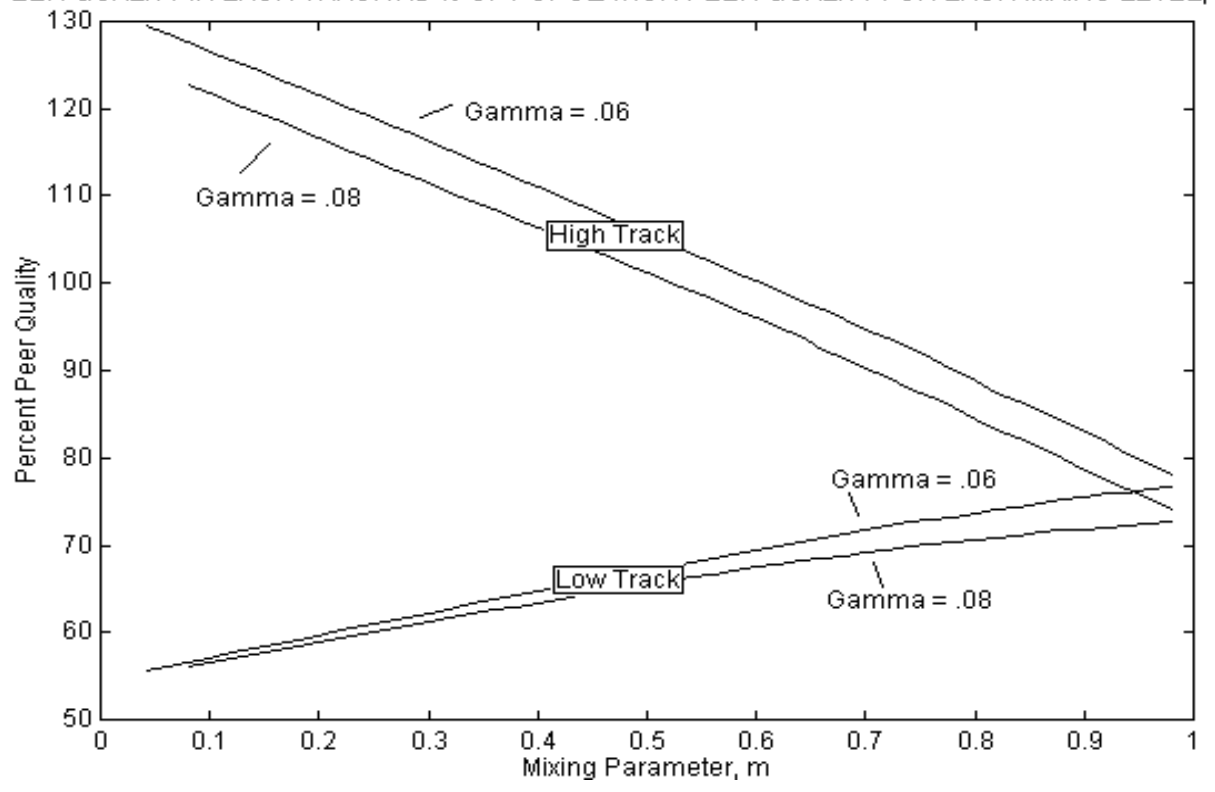




\section{Figure 5:}

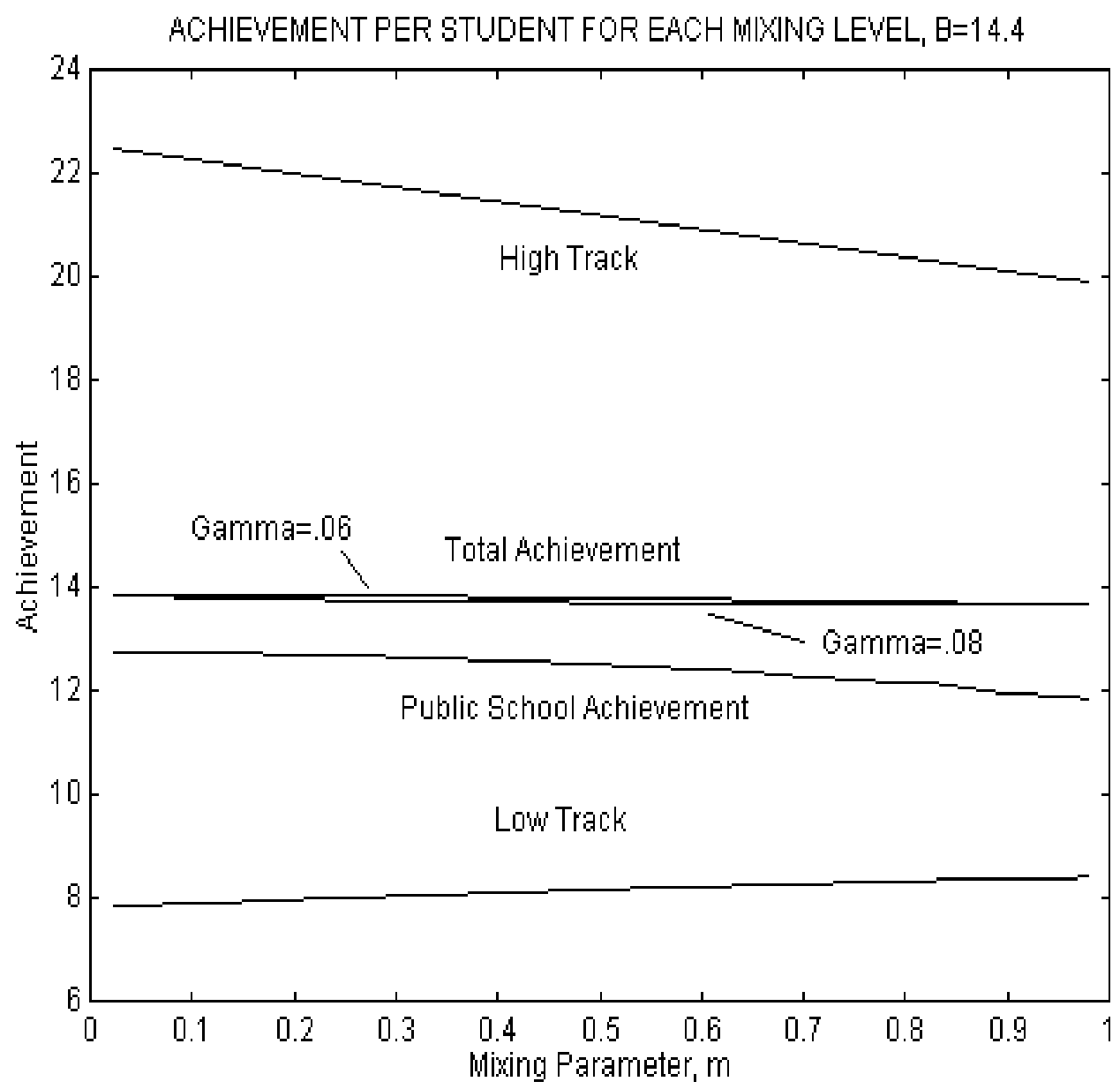




\section{F1gure 6:}
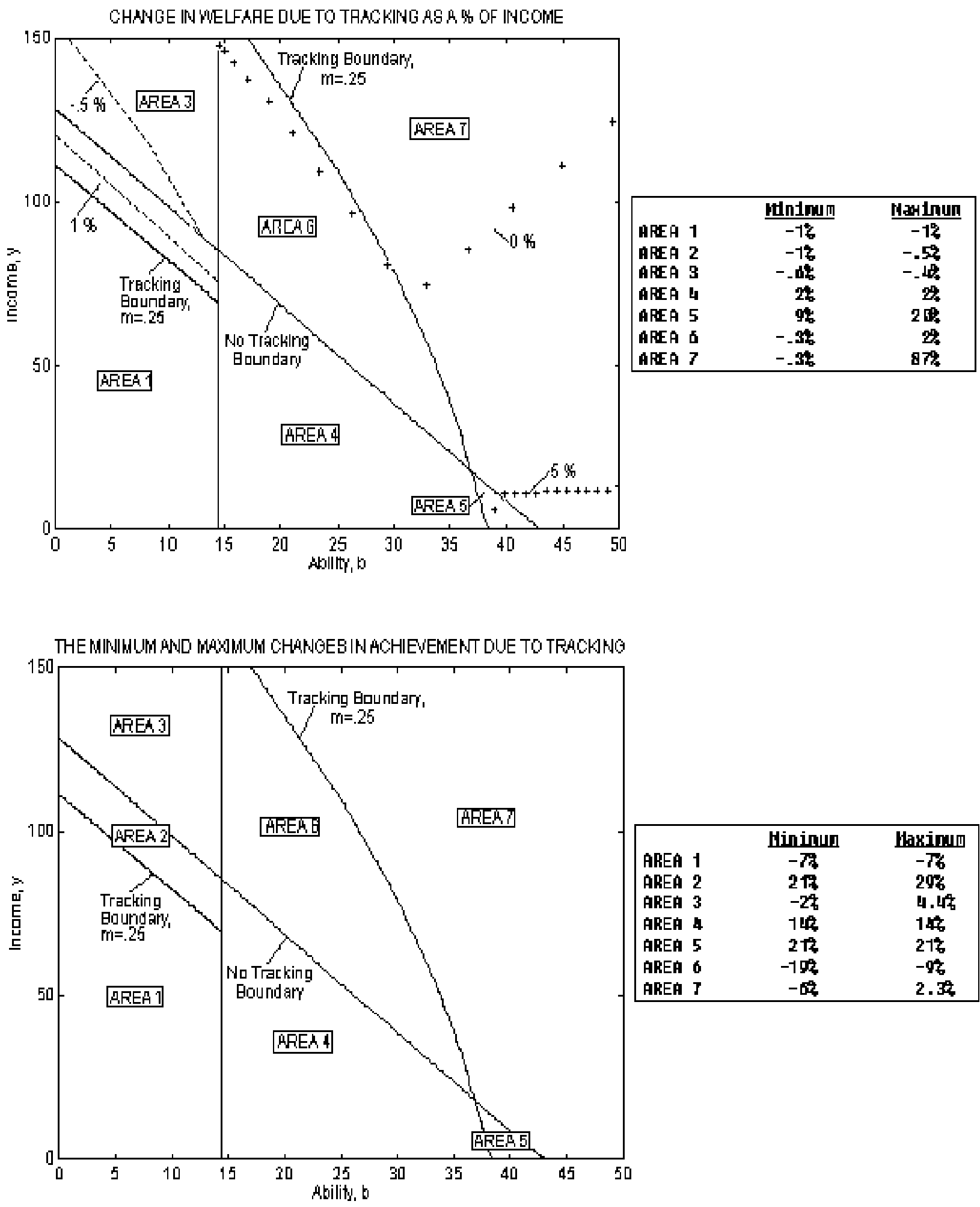

\begin{tabular}{|c|c|c|}
\hline & Hininul & Hamipum \\
\hline AREA 1 & -7 & $-\sqrt{6}$ \\
\hline AREA 2 & 217 & 296 \\
\hline AREA 3 & -24 & 4.44 \\
\hline AREA 4 & 14 & 14 \\
\hline AREA 5 & $2 \hat{2}$ & $21 \frac{6}{6}$ \\
\hline AREh 6 & -104 & $-9 t$ \\
\hline ARER $T$ & -6 & 2.34 \\
\hline
\end{tabular}




\section{Figure 7:}

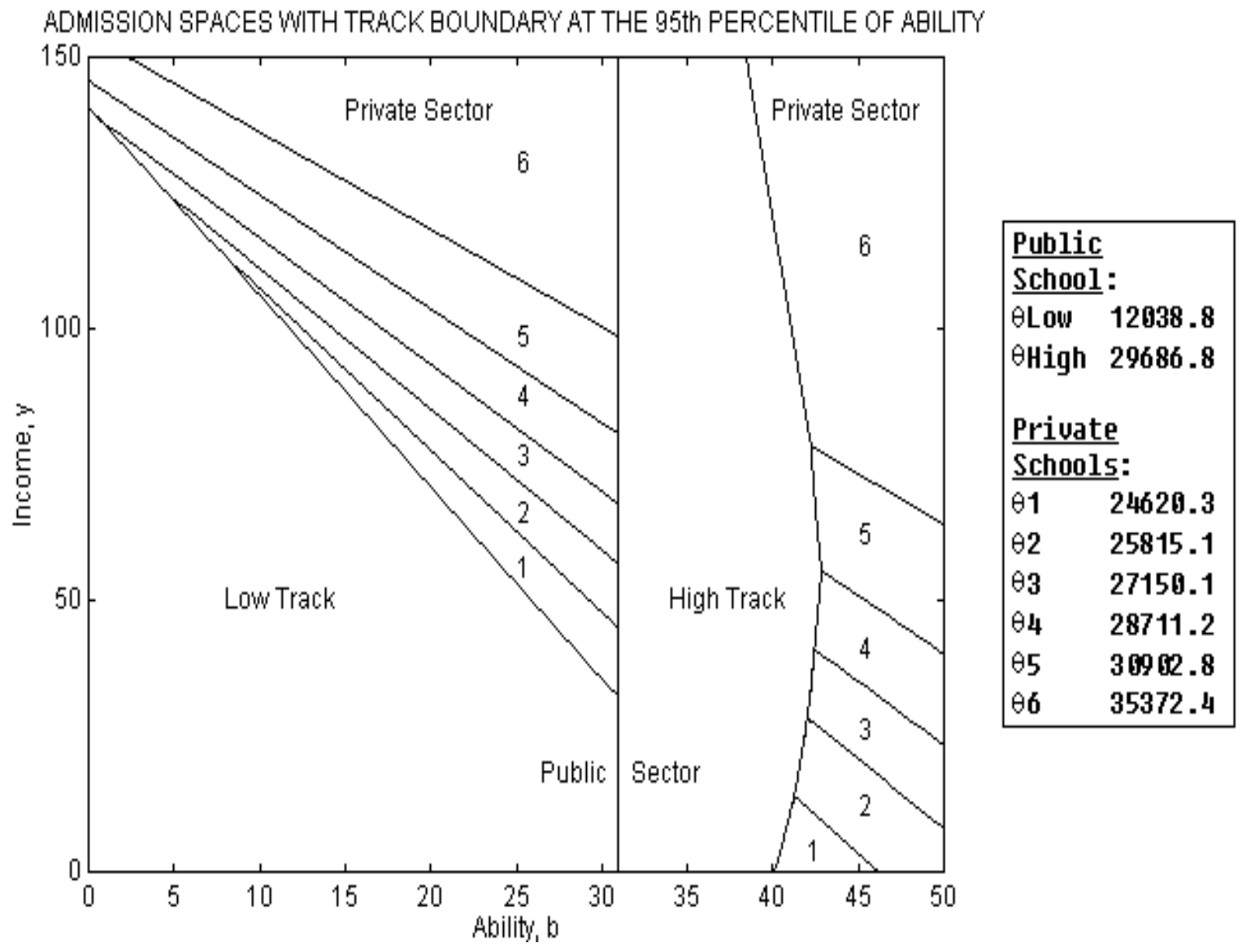




\section{Figure 8:}

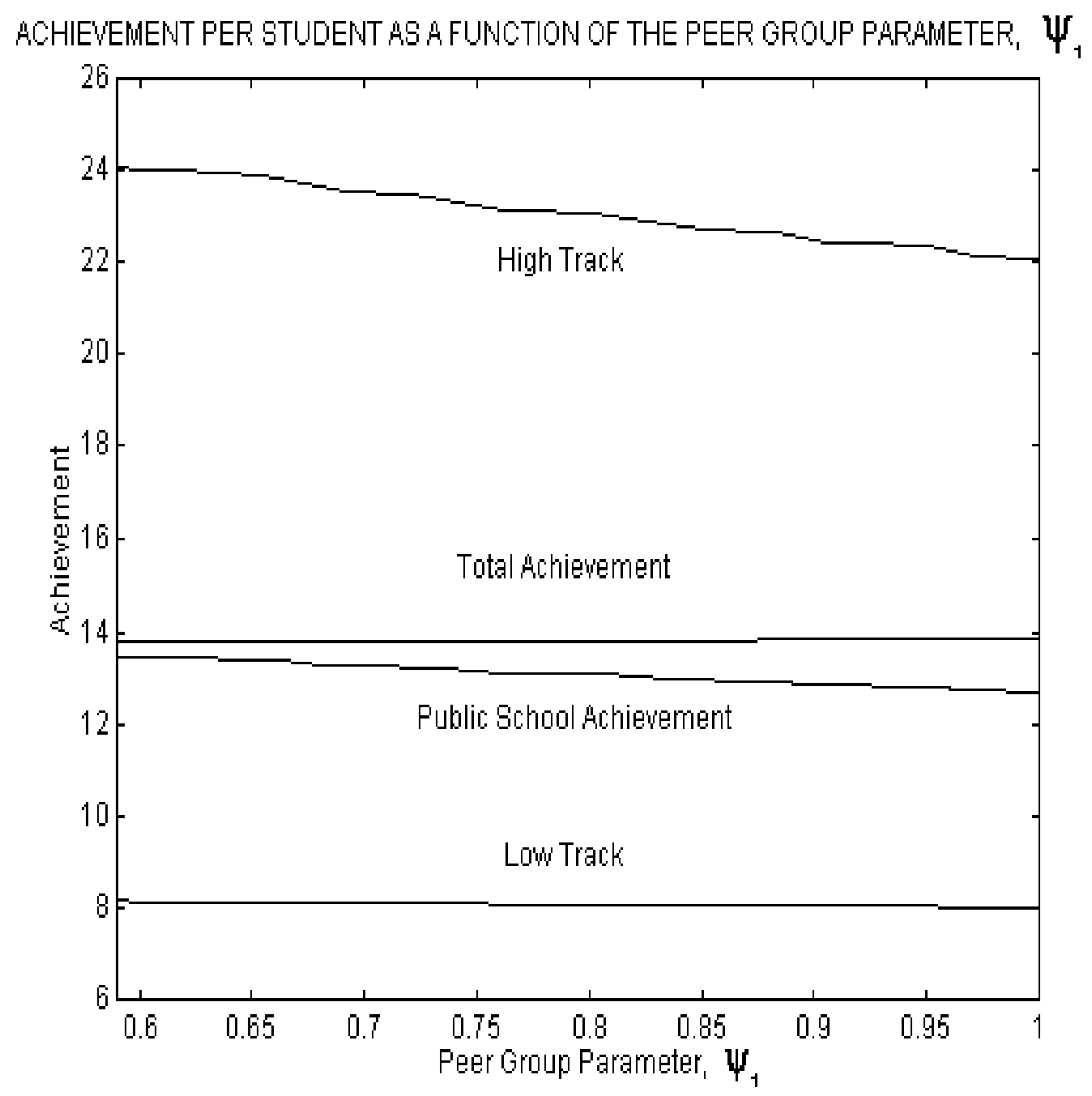


Table 1: Equilibrium with Different Degrees of Mixing Across Tracks

\begin{tabular}{|c|c|c|c|c|c|c|c|c|c|}
\hline \multirow{3}{*}{ Low PublicTrack } & \multicolumn{3}{|c|}{ Complete Mixing $(m=1) *$} & \multicolumn{3}{|c|}{ Benchmark Equilibrium $(m=.25)$} & \multicolumn{3}{|c|}{ No Mixing $(\mathrm{m}=\mathbf{0})$} \\
\hline & $\begin{array}{l}\text { Proportion } \\
\text { of Students } \\
\qquad\left(\mathrm{k}_{\mathrm{i}}\right)\end{array}$ & $\begin{array}{c}\text { Track/School } \\
\text { Quality } \\
\left(\theta_{\mathrm{i}}\right)\end{array}$ & $\begin{array}{l}\text { Discount to One } \\
\text { Standard } \\
\text { Deviation Rise in } \\
\text { Ability }\end{array}$ & $\begin{array}{c}\text { Proportion } \\
\text { of Students } \\
\qquad\left(\mathrm{k}_{\mathrm{i}}\right)\end{array}$ & $\begin{array}{c}\text { Track/School } \\
\text { Quality } \\
\left(\theta_{\mathrm{i}}\right)\end{array}$ & $\begin{array}{l}\text { Discount to One } \\
\text { Standard } \\
\text { Deviation Rise } \\
\text { in Ability }\end{array}$ & $\begin{array}{c}\text { Proportion } \\
\text { of Students } \\
\qquad\left(\mathrm{k}_{\mathrm{i}}\right)\end{array}$ & $\begin{array}{c}\text { Track/School } \\
\text { Quality } \\
\left(\theta_{\mathrm{i}}\right)\end{array}$ & $\begin{array}{l}\text { Discount to One } \\
\text { Standard } \\
\text { Deviation Rise in } \\
\text { Ability }\end{array}$ \\
\hline & .632 & 12.15 & & .616 & 9.596 & & .606 & 8.564 & \\
\hline High Public Track & .273 & 12.15 & & .309 & 18.70 & & .308 & 20.62 & \\
\hline Private School 1 & .010 & 25.45 & $\$ 2,237$ & .010 & 22.85 & $\$ 2,510$ & .010 & 20.84 & $\$ 2,583$ \\
\hline Private School 2 & .010 & 26.02 & $\$ 2,292$ & .0099 & 23.97 & $\$ 2,619$ & .010 & 21.90 & $\$ 2,692$ \\
\hline Private School 3 & .0099 & 26.68 & $\$ 2,365$ & .0098 & 25.17 & $\$ 2,710$ & .010 & 22.89 & $\$ 2,783$ \\
\hline Private School 4 & .0098 & 27.43 & $\$ 2,437$ & .0096 & 26.59 & $\$ 2,819$ & .0099 & 23.99 & $\$ 2,874$ \\
\hline Private School 5 & .0097 & 28.33 & $\$ 2,510$ & .0094 & 28.34 & $\$ 2,947$ & .0097 & 25.31 & $\$ 2,965$ \\
\hline Private School 6 & .0096 & 29.43 & $\$ 2,601$ & .0091 & 30.81 & $\$ 3,074$ & .0095 & 27.04 & $\$ 3,074$ \\
\hline Private School 7 & .0095 & 30.88 & $\$ 2,710$ & .0082 & 35.63 & $\$ 3,292$ & .0092 & 29.45 & $\$ 3,219$ \\
\hline Private School 8 & .0092 & 33.02 & $\$ 2,856$ & & & & .0082 & 34.25 & $\$ 3,438$ \\
\hline Private School 9 & .0083 & 37.59 & $\$ 3,074$ & & & & & & \\
\hline
\end{tabular}

*The proportions in the low (high) public tracks under complete mixing are the population proportions in the public school with ability below (above) $\mathrm{B}=14.4$. 
Table 2: Track Attendance By Income Quartile

$$
\underline{\rho=0}
$$

Lowest Quartile
Quartile 2
Quartile 3
Quartile 4

\begin{tabular}{c} 
Percent Low Track Students \\
\hline 26.4 \\
26.5 \\
26.5 \\
20.6
\end{tabular}

$\underline{\text { Percent High Track Students }}$ 26.1 25.5 25.3

23.1

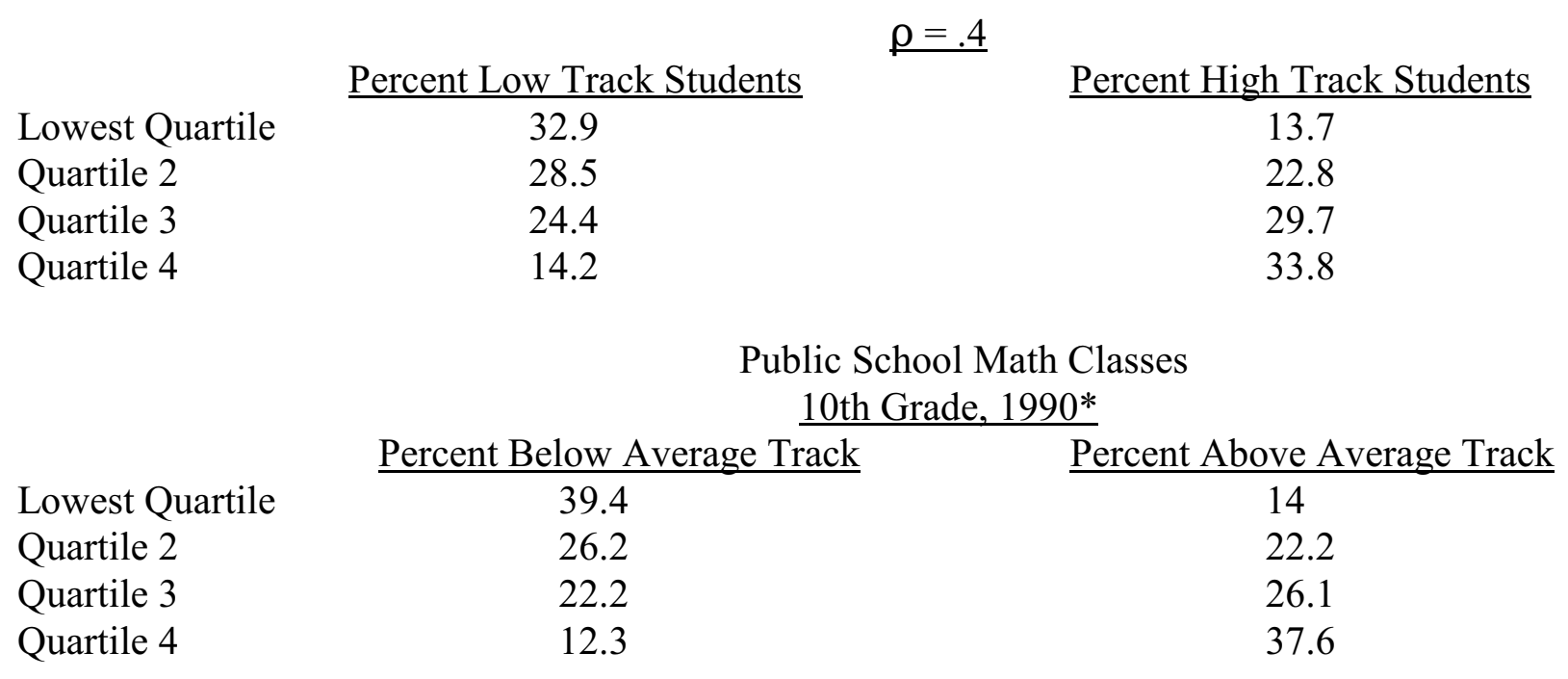

*Adapted from Rees, Argys, and Brewer (1996), Table 4 (p. 85). Teachers classified classes as below average, average, above average or heterogeneous. If the below average and average tracks are combined, the percentages by income quartiles equal 28.5, 25.6, 24.3, and 21.5 from lowest to highest. 


\section{Footnotes}

1. Tracking is a common practice in other countries as well. See Oakes, Gamoran, and Page, 1992.

2. Ability tracking at the elementary level is also common in public schools (see, e.g., Oakes, et.al.).

3. Gamoran (1992) measures four structural properties of tracking identified by Sorenson (1970), termed selectivity, electivity, inclusiveness, and scope. Selectivity and inclusiveness measure how elitist the tracking system is and are parameterized in our model by the track boundary discussed below. Electivity measures students' power to select tracks which our model does not permit. Gamoran's measures indicate little variation in electivity in tracking. Scope concerns the extent to which tracking encompasses subjects, a key variable we study.

4. Coleman and Hoffer (1987) report that, in 1982, 62.8 percent of public high schools students attended schools that grouped students by ability while 43.4 percent of non-Catholic private school students attended schools that so grouped students (Table 2.11, p. 45). Combining primary and secondary schools, 74.9 percent of public schools offered gifted programs and 60.3 percent remedial math in 1990-91 with the respective corresponding percentages for all private schools 29.5 and 42.4 (Private School in the United States: A Statistical Profile, 1990-91, Table 1.9, pp. 25-26). (The corresponding percentages for nonsectarian private schools are 31.2 and 39.7.) While Coleman and Hoffer report that the percentage of students in Catholic high schools that are ability grouped was about the same as in public schools in 1982, the percentage of students they classify as enrolled in academic programs are 35.7, 72.1 and 71.1 in public, Catholic, and other private schools respectively (Table 2.9, p. 43). These numbers suggest that fewer Catholic school students are affected by ability grouping, that tracking in Catholic schools is more inclusive and less selective (see footnote 3 ).

5. Oakes, et.al. provide a survey of the literature. A sophisticated analysis of optimal grouping and optimal allocation of resources across students in a school with exogenously determined distribution of student types is provided by Arnott and Rowse (1987).

6. While evidence on tracking practices is relatively well established, evidence about the effects of tracking on educational outcomes is less so, largely because research on the latter is bedeviled by the difficulty of controlling for selection effects. Much of the literature (see Argys, Rees, and Brewer, 1996; Moreland and Levine, 1992) concludes that, relative to outcomes in mixed classes, students assigned to low tracks are hurt by tracking while those assigned to high tracks gain. These findings are consistent with our model. We note, however, others (e.g., Figlio and Page, 1999) find beneficial effects to students assigned to the low track.

7. Given an objective function for public schools (e.g., maximizing attendance or average achievement), public school tracking can be endogenized. Since it is unclear what objective function should be attributed to the public school sector, we choose instead to vary public school tracking parametrically and characterize how such variation affects attendance, achievement, and other aspects of the equilibrium.

8. See also Nechyba (1999) and Caucutt (1998) for similar models of provision of education without tracking.

9. Epple and Romano (1999) extend the model to variation in per student expenditure. 
10. Households may consider education a consumption good, an investment good, or a combination of the two. Our formulation can be interpreted to accommodate any of these motives. However, for households not subject to borrowing constraints, a pure investment motive would imply a zero income elasticity of demand. For such households, this in turn would imply that the SCI condition would be only weakly satisfied. In light of the empirical evidence suggesting the income elasticity to be positive, we conserve space in the development that follows by assuming SCI is strict for all households. See Haveman and Wolfe (1984) for a discussion of what underlies the demand for education.

11. Henderson, et al., (1978) find no interaction between own ability and the benefits to an improved peer group, corresponding to $\frac{\partial^{2} U}{\partial \theta \partial b}=0$ in our model. Argys, et. al.'s (1996) findings suggest $\frac{\partial^{2} U}{\partial \theta \partial b}>0$. Summers and Wolfe (1977) find some support for higher peer group benefits to lower ability students, i.e., $\frac{\partial^{2} U}{\partial \theta \partial b}<0$. Thus the literature provides no clear evidence from which to draw conclusions.

\section{Heterogeneous public schools are discussed in Section 5.}

13. We assume that ability is observable, e.g., through testing. Note that there is no incentive to under-perform on placement tests.

14. Consideration of alternative objective functions to profit maximization is reasonable, especially given the significant proportion of nonprofit schools. Some private schools might, for example, pursue the objective of quality maximization. Quality maximization, like profit maximization, is a member of a set of objective functions that are utility independent in the sense that they place no weight on offering any student types higher utility than the student's (equilibrium) reservation utility. Our analysis of this issue suggests that equilibria where some private schools pursue objectives from this set other than profit maximization must also be competitive equilibria. The failure of any school to maximize profits would permit entry by a profit-maximizing school.

15. As observed in footnote 13, abilities can be determined through testing, and we assume further that financial disclosures required by private schools permit determination of household income.

16. One might argue that this recognition of the limits on demand is inconsistent with a competitive specification. The presumption is similar to that of a monopolistically competitive seller who recognizes the limit to demand. Absent the assumption, private schools wish to admit an infinite number of almost every type that attends their school.

17. If tuitions equal EMC's for every student in private schools, the EMC's recalculated given the latter tuition restriction, the allocation will not be exactly the same because households' real incomes will change some and affect demands for school quality. From a normative perspective, this is an equity issue not an efficiency one. From a positive perspective, these effects will be very small in a realistically calibrated model.

18. For Cobb-Douglas specification of utility/achievement in (2), Epple and Romano (1998) prove SBA without ascending $\eta$ 's, substituting the requirement that $b$ and $y$ are stochastically 
independent in the population.

19. The linear boundary loci derive from the Cobb-Douglas preference specification in the computational analysis.

20. When $\mathrm{m}=1$, there is a degree of freedom in the choices of $\mathrm{k}_{\ell}$ and $\mathrm{k}_{\mathrm{h}}$ since all that is relevant is their sum.

21. A stigma from assignment to a lower track in a private school might also help limit tracking as noted above. This demand-side diseconomy is similar to diseconomies of scope.

22. Sufficiently high-income students who qualify for the upper track will choose the free public sector even though they might face negative tuition at a lower-quality private school.

23. The generalization described here was originally developed in Epple and Romano (1999), but is only applied to tracking here.

24. A caveat about our generalization concerns its assumption that students of all types agree on ordinal school/track quality. A single measure of quality can still be used. Another specification assumes types assess peer quality differently, perhaps with both variability in abilities and differences from own ability reducing a type's educational achievement. Each type's ideal could have peer students all of the student's own ability. Models with quality that varies across student types are an interesting topic for research.

25. Recent evidence (Solon, 1992; Zimmerman, 1992) indicates that the correlation between father's income and son's income is approximately .4. This correlation is an upper bound on the correlation between father's income and son's ability because the intergenerational correlation of income arises both from intergenerational correlation of ability and from the choice of higher quality private schools by some higher income households.

26. At the efficient scale, the cost function implies an average cost of $\$ 4200$ per student. Using $1 / 2$ student per household, substituting for $\mathrm{k}$ in the cost function confirms this.

27. The choice of efficient scale is somewhat arbitrary. By sensitivity analysis we have found that, as long as the minimum of average cost is unchanged, equilibrium allocations are relatively insensitive to variations in efficient scale, at least for values of $k^{*}$ up to 4 percent of the population. The equilibrium number of private schools does vary with $\mathrm{k}^{*}$ (but the allocation of students between the public and private sectors does not vary significantly), and we have chosen $\mathrm{k}^{*}$ so that there are enough private schools to make their presumed utility-taking behavior reasonable.

28. In Epple and Romano (1998), we largely avoid crossing of indifference loci due to no tracking and a calibration with larger efficient scale. We can then calculate pricing functions with income discrimination, and we find this discrimination to be of limited consequence even with larger private schools than here.

29. Formally, the cost of a school that runs both tracks is given by: $\mathrm{C}\left(\mathrm{k}_{\ell}, \mathrm{k}_{\mathrm{h}}\right)=\mathrm{MIN}$ $\left[\left(\mathrm{N}_{\ell}+\mathrm{N}_{\mathrm{h}}\right) \mathrm{F}+\mathrm{V}\left(\mathrm{k}_{\ell} / \mathrm{N}_{\ell}\right)+\mathrm{V}\left(\mathrm{k}_{\mathrm{h}} / \mathrm{N}_{\mathrm{h}}\right)\right]$ for $\left(\mathrm{N}_{\ell}, \mathrm{N}_{\mathrm{h}}\right)$ integer valued, where $\mathrm{N}_{\mathrm{i}}$ is the number of homogeneous tracks $i \in\{\ell, h\}$ that the school runs. 
30. The average loss in compensating variation from tracking among all those who fail to qualify for the upper track equals $\$ 474$, and the average gain to those who qualify equals $\$ 680$. The average among everyone is a loss of $\$ 70$. Hence, like achievement, the average welfare effect is small, about .2 percent of mean income.

31. Absent such a normalization, school qualities decline as $\psi_{1}$ declines for any allocation of types into schools. This would confound the effects of variability with those of an independent lowering of school qualities. Our normalization is discussed in more detail in an appendix available on request.

32. See Suro (1992) for an example in this spirit. 